\title{
Circulation on the Northwestern Iberian Margin: Vertical Structure and Seasonality of the Alongshore Flows
}

\author{
Ana Teles-Machado ${ }^{\mathrm{a}}$, Álvaro Peliz ${ }^{\mathrm{a}}$, James C. McWilliams ${ }^{\mathrm{b}}$, Xavier \\ Couvelard $^{\mathrm{c}, \mathrm{d}}$, Isabel Ambar \\ ${ }^{a}$ Instituto Dom Luiz, Faculdade de Ciências, Universidade de Lisboa, Lisboa, Portugal \\ ${ }^{b}$ Institute of Geophysics and Planetary Physics, University of California, Los Angeles, Los \\ Angeles, California, USA \\ ${ }^{c}$ Center for Mathematical Sciences, Universidade da Madeira, Portugal \\ ${ }^{d}$ IFREMER/DYNECO-PHYSED Centre Ifremer de Brest, Plouzané, France \\ ${ }^{e}$ MARE - Centro de Ciências do Mar e Ambiente, Faculdade de Ciências, Universidade de \\ Lisboa, Lisboa, Portugal
}

\begin{abstract}
We describe the seasonal cycle of the alongshore flows on the Northwestern Iberian Margin and explain what are the important mechanisms forcing the system. We used a 20-year model simulation at $2.3 \mathrm{~km}$ horizontal resolution, with realistic atmospheric forcing and covering the whole Western Iberian Margin. The model results are compared with satellite data, with data measured at two moored buoys and with a compilation of current meter data available for the study region. We show that currents over the slope are divided in three different cores: the Iberian Poleward Current (IPC) occupying the top $350 \mathrm{~m}$, a deeper core at Mediterranean Water levels ( 600-1200 m) and in between the two, an equatorward core centered just beneath the IPC core, the Upper Slope Countercurrent (USCC). The IPC is present almost yearlong, including in summer months, when it is close to the shelf-break and topped by the equatorward upwelling jet. After September, the IPC intensifies and its core surfaces. Heat and salinity budgets on the shelf and slope are dominated by advection, confirming the important role of the IPC in driving the temperature and salinity seasonal cycles. Analysis of the seasonal cycle of the barotropic vorticity equation on the slope, shows that the main forcing mechanism of northward flows is the "Joint Effect of Baroclinicity and Relief" (JEBAR), whose contribution is
\end{abstract}

Preprint submitted to Progress in Oceanography

May 7, 2015

(C) 2015. This manuscript version is made available under the Elsevier user license http://www.elsevier.com/open-access/userlicense/1.0/ 
higher in summer than in winter. In December and January, when the IPC is stronger and surface intensified, the main contribution is from southerly winds. The cross-shore analysis of these terms shows that JEBAR decreases substantially at the core of the IPC because, as advection terms become important, the northward density flux diminishes the local meridional density gradients, resulting in the decrease of JEBAR in the months of strong IPC.

Keywords: Slope currents, Seasonality, Northwestern Iberia, Ocean-atmosphere system

\section{Introduction}

The Western Iberian Margin is characterized by persistent, multicore seasonally varying flows. The summer is dominated by upwelling-type shelf circulation with associated equatorward surface currents, cold water fronts, filaments and eddies (Haynes et al., 1993; Relvas and Barton, 2002; Peliz et al., 2002). Fig. 1 (left) shows the average July SST, with cold waters near the coast, and with a schematic representation of the southward flowing upwelling jet over the shelf. The Iberian Poleward Current (IPC) dominates the winter circulation over the upper slope and outer shelf. This current was described in observational and numerical studies (Frouin et al., 1990; Martins et al., 2002; Peliz et al., 2003a.b, 2005; Torres and Barton, 2006; Friocourt et al., 2007, 2008b. a). The IPC extends to the northern coast of the Iberian Peninsula, usually in December or January, as a narrow surface-intensified current noticeable for its warm Sea Surface Temperature (SST) signature all along the northern Iberian Margin (Pingree and Le Cann, 1990, 1992b; Friocourt et al., 2008b; Le Cann and Serpette, 2009). Pingree and Le Cann (1992a) named this warm water intrusion in the north coast as Navidad, because it occurs near Christmas. Fig. 1 (right) shows the average January SST, with warm waters over the shelf and slope, and with a representation of a schematic IPC. At intermediate levels ( $\sim 800-1200 \mathrm{~m})$, the water also circulates poleward along the western Iberian slope, transporting the warm and saline Mediterranean Water (Daniault et al., 1994; Ambar and Fiúza, 
1994). In this study we will refer to it as the Iberian Poleward Slope Undercurrent (IPSU).

The mechanisms that force the IPC are still not completely clarified. Peliz et al. with a surface intensified meridional density gradient characteristic of the region, results in the development of a surface intensified poleward current over the slope, in the upper $350 \mathrm{~m}$ of the water column, with a weak equatorward current developing just beneath. Friocourt et al. (2008b) use both analytical and numerical model approaches, of a 4-layer system, with meridional density gradients of alternating signs in depth, and reproduce a baroclinic system of slope currents with alternating directions, the surface one flowing poleward. The "Joint Effect of Baroclinicity and Relief" (JEBAR) (Huthnance, 1984) is the main driving mechanism in those two studies. On the other hand, Frouin et al. (1990), Le Cann and Serpette (2009) and Garcia-Soto and Pingree (2011) argue that southerly winds are important for the development of surface intensified events of the IPC.

Despite the existence of many observational and modeling studies of this region, a systematic study of the mean structure and seasonal variability of the whole alongshore system was still missing. We use a high resolution realistic numerical model together with current meter observations, to characterize the vertical structure of the mean alongshore flow and its mean seasonal variability. The main questions addressed are: 1) How does the system evolve in the Spring and Autumn transitions? 2) What happens to the IPC in summer, when the shelf is dominated by southward currents? 3) What is the role of the IPC in driving the temperature and salinity seasonal variability? And finally, 4) What are the main forcings of the IPC and how do they vary seasonally?

In the next section, we present a description of the numerical model, the observed data, the model configuration details and the comparison of model results with the observations. In section 3 , we present the model results. In section 4, we analyze the vorticity balances. Section 5 is the discussion and comparison with previous studies of the region and section 6 , the summary and 
conclusions.

\section{Model, configuration and observed data}

55 2.1. Model

The Regional Ocean Modeling System (ROMS), is a primitive equation, hydrostatic, sigma coordinate, free-surface ocean model (Shchepetkin and McWilliams, 2005; Shchepetkin and McWilliams, 2003; Hedstrom, 2009). The need for solving processes at a wide range of horizontal spatial scales led us to use nested grids because of its nesting capabilities (Debreu et al., 2012).

ROMS uses a third-order upstream momentum and tracers advection scheme, which is dissipative in nature, allowing a simulation without explicit viscosity or diffusivity. The subgrid-scale vertical mixing processes in the interior and in the boundary layers are parameterized with a K-profile parametrization scheme (Large et al., 1994). ROMS uses a split-explicit time-step, that integrates the barotropic equations with a shorter time-step than the baroclinic equations.

This model configuration was developed in two phases. The first, was a large scale climatological simulation using the large domain represented in Fig. 2/(grid $\mathrm{C} 0$ ), to produce equilibrium solutions for initialization and boundary conditions. The second phase consists of a high resolution 2-way nested realistic simulation (domains represented in Fig. 2- grids A0 and A1), initialized and forced on the boundaries by the outputs of the climatological run.

\subsection{Climatological Simulation}

For the domain $\mathrm{C} 0$, we ran a 10 -years simulation, with horizontal grid resolution of $1 / 10^{\circ}$, which corresponds to approximately $7.5 \mathrm{~km}$ near the northern boundary and $10 \mathrm{~km}$ in the south. This results in a horizontal grid with $449 \times 311$ cells. In the vertical direction, the grid has 32 levels with enhanced resolution near the surface (the surface stretching parameter is $\theta_{S}=6$ and the bottom stretching parameter $\theta_{B}=0$ ) to better resolve the surface boundary 
layer everywhere in the domain. The baroclinic time step is 1080 seconds and the barotropic is 18 seconds. The model grid, forcing, initial and climatology files were built using the ROMSTOOLS package (Penven et al., 2008). The topography was derived from database ETOPO2 (National Geophysical Data Center - NGDC), smoothed and interpolated to the model grid. The model was initialized with Levitus climatology (WOA05 - Locarnini et al. (2006) and Antonov et al. (2006)) in January. Along the open boundaries a modified radiation boundary condition was used together with a flow adaptive nudging to the Levitus climatology (Marchesiello et al., 2001). The nudging is stronger in case of inflow in the open boundaries and weaker in case of outflow, respectively with time scales of 1 day and 1 year for tracers and 10 days and 1 year for momentum. Regarding the external forcing, the momentum, heat and freshwater fluxes were extracted from the Comprehensive Ocean-Atmosphere Data Set (COADS) monthly climatology at $1 / 2^{\circ}$ resolution (da Silva et al., 1994). The the divergence of the model solution from the Levitus climatology. The implemented nudging condition is described in Peliz et al. (2007). After a spin-up of around 2 years, the volume averaged kinetic energy of the simulation reaches an equilibrium (not shown). Years 4 to 7 of this simulation were used to create a monthly climatology for the high resolution domains A0 and A1 (see Fig. 22). This period was chosen because the model had already reached an equilibrium state and had not diverged significantly from the climatology.

\subsection{Two-way nesting simulation}

This simulation uses a larger domain (represented as A0 in Fig. 2) and an embedded child domain (represented as A1 in Fig. 2), running simultaneously and exchanging information between each other at every model time-step. A0 spans from $33^{\circ} \mathrm{N}$ to $46^{\circ} \mathrm{N}$ and $18^{\circ} \mathrm{W}$ to $1^{\circ} \mathrm{W}$, with an horizontal resolution within the range of 6.4 to $7.8 \mathrm{~km}(205 \times 205$ grid cells $)$. A1 spans from $34.8^{\circ} \mathrm{N}$ to $45.0^{\circ} \mathrm{N}$ and $13.6^{\circ} \mathrm{W}$ to $3.4^{\circ} \mathrm{W}$, with horizontal resolution from 2.2 to $2.5 \mathrm{~km}(368 \mathrm{x} 482$ grid cells). In the vertical, the grids have 40 levels and the same stretching 
parameters were used as for the climatological simulation. The baroclinic time steps are 900 seconds and 300 seconds, and the barotropic time steps are 15 seconds and 5 seconds, for grids A0 and A1, respectively. The model grids were also built using the ROMSTOOLS package (Penven et al., 2008). The topography was derived from Scripps Institution for Oceanography global topography (Smith and Sandwell, 1997) and from Spanish data for the Strait of Gibraltar (Sanz et al., 1991). The merged topography was smoothed to avoid pressure gradient errors, so that the slope parameter (Beckmann and Haidvogel, 1993) is everywhere lower than 0.19 .

Radiation condition plus flow adaptive nudging towards a monthly climatology, were used along A0 open boundaries (Marchesiello et al., 2001). The monthly climatology was created from the outputs of the climatological simulation. No interannual variability is introduced to the domain from the open ocean, through the open boundaries.

Zero explicit viscosity and diffusivity were used everywhere, except in a sponge layer of 50-km width along the open boundaries of domain A0 (see Fig. 21). Increased values of viscosity and diffusivity were applied in the Gulf of Cadiz near the Strait of Gibraltar to produce a more realistic representation of the Mediterranean Undercurrent (Peliz et al., 2012) and near the mouth of river inputs, as will be explained in the next sections. In the sponge layer, the viscosity increases smoothly from zero in the interior to $300 \mathrm{~m}^{2} \mathrm{~s}^{-1}$ in the boundary.

\subsection{Atmospheric Forcing}

The atmospheric forcing was created using the outputs of a Weather Research and Forecast (WRF) model simulation, covering the period from 1989 to 2008 with hourly outputs and with horizontal resolution of $27 \mathrm{~km}$ (Soares et al., 2012). The variables used were the wind at $10 \mathrm{~m}$, the temperature and the specific humidity at $2 \mathrm{~m}$, the precipitation, the short wave net radiation and incident long wave radiation. The fluxes of momentum and sensible and latent 
bulk formulation (Fairall et al., 1996; Liu et al., 1979). The upward long wave radiation is also computed internally in the model, using the Stefan-Boltzmann law with the computed sea surface temperature (SST).

\subsection{Rivers and Mediterranean Outflow}

The rivers that discharge a significant amount of fresh water to the coastal ocean are the Tejo, Mondego, Douro, Ave, Cávado, Lima, Minho, together with smaller ones that discharge into the Galician Rias (the Tambre, Ulla, Umia, Lérez and Verdugo) (subplot on the right in Fig. 2) and the Guadalquivir. Due to recurrent and extensive gaps in river outflow data, we used climatologies of river discharges; we obtained the polynomials that adjust to the seasonal cycles and used these analytical adjustments to simulate the runoff in the model. For the northwestern Iberian rivers, data from Otero et al. (2010) were used (the Douro River was the southernmost one considered in this study). Runoff data for the Mondego and Tejo Rivers were obtained from Chainho et al. (2006) and Neves (2010), respectively. The Guadalquivir is not shown in Fig. 2 because it is out of the zoom area on the right, but it was also considered in the simulation.

The rivers were introduced using a depth-uniform outflow, with a constant velocity profile. To get realistic values for the salinity of the river plumes it was necessary to increase mixing near the river mouths. In nature, many of these rivers discharge in estuaries where fresh water is strongly mixed with sea water, due to tide effects, strong currents and atmospheric heat forcing, but because of their small size, the estuaries are not resolved in this simulation. To represent the unresolved mixing processes we introduced a circular region with increased horizontal diffusion near the mouth of all the rivers, whose radius and intensity vary in time, proportionally to the intensity of the river outflow. To guarantee a realistic Mediterranean outflow, we used the same procedure as in Peliz et al. (2012).

\subsection{Spin-up}

A spin-up of 2 years was done, already taking into consideration the rivers and Mediterranean outflow as described. The atmospheric forcing, momentum, 
heat and freshwater fluxes were from the Comprehensive Ocean-Atmosphere Data Set (COADS). After the spin-up, the model ran for 20 years, 1989 to 2008 , which is the period analyzed in this paper.

\subsection{Observed data}

We used data from a set of historical moored current meter observations from 1984 to 1995. The data were collected in the frame of different projects (CORPAC, MORENA, Bord-Est1 and MEDPOR) and are described in Ambar (1985), Ambar and Fiúza (1994), Daniault et al. (1994) and Frouin et al. (1990). The location of the moorings is represented in Fig. 2. The time periods and depths of the current meters are shown in Fig. 3. We have a total of 4995 days of observations distributed over the various locations, depths and times. We use these data to compute monthly averages for each of the current meter locations, to compare with the seasonal cycle of the model in the same locations.

Model currents, temperature and salinity are also compared with data measured at $3 \mathrm{~m}$ depth, at the buoys of the Spanish Public Agency of Marine Affairs, Puertos del Estado (http://www.puertos.es/en). Figure 2 shows the positions of the buoys Cabo Silleiro and Villano Sisargas, represented respectively as 1 and 2. These data are available from 1998 to the end of the model simulation, depending on the variable (see Fig. 4). We also compared the modeled winds with the winds measured at the buoys. To compare the buoys winds (measured at $3 \mathrm{~m}$ height) with the modeled winds used to force the ocean model (at $10 \mathrm{~m}$ height), the buoys winds were corrected to $10 \mathrm{~m}$ height, considering a neutral logarithmic profile and having in consideration the effects of waves on the distortion of the wind profile (Large et al., 1995). The wave significant height data, used to correct the wind profiles, was also obtained at the same buoys.

We also use altimetry data to compare with the seasonal cycle of the model sea surface height anomaly. The altimeter products were produced by Ssalto/Duacs and distributed by Aviso, with support from Cnes (http://www.aviso.oceanobs.com/duacs/). The maps have a spatial resolution around $28 \mathrm{~km}$ and a time resolution of one week. 
Model SST was compared with nighttime SST from AVHRR Pathfinder Version 5.2 (PFV5.2) data, obtained from the US National Oceanographic Data Center and GHRSST (http://pathfinder.nodc.noaa.gov) (Casev et al., 2010). 5day averaged data was downloaded and averaged to obtain monthly data. We only considered the best quality SST estimates, eliminating all data with a quality-flag inferior to 7 .

\subsection{Comparison with observations}

Figure 5 shows a comparison between model and current meter time series statistics for the meridional (approximately alongshore) velocity component. Each subplot corresponds to a current meter location and depth (see Figure 3). We computed monthly averages of the current meter alongshore velocity whenever there was a minimum of 14 days of data per month (missing points correspond to values below that threshold). We also computed monthly averages of the model at the locations of the current meters. In general, for the 3 latitudes, the current meter averages lie inside the shaded area, which demarcates the minimum and maximum values of the monthly averages obtained for each month on the 20-year model run. The values of the root mean square error RMSe are shown on the plots, as a measure of correspondence between model and observations. The quantities are not exactly equivalent, since the model monthly averages are computed using 20 years of outputs, and the monthly averages of the observations are computed using the period available for each location, which is never longer than 2 years.

For the current meters located at $42.2^{\circ}$ (Fig. [5- first column) the match is better in the current meter a) (at $464 \mathrm{~m}$ depth), in which model and observations show a similar seasonal evolution, especially from July to October.

Some of the variability obtained in the model results are also present in the

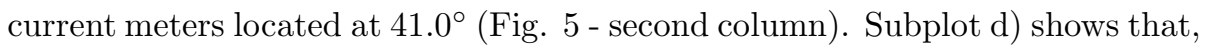
at 100 metres depth, the flow is already northward in August, confirming the presence of poleward velocities over the upper slope / shelf break as obtained 
data and model, except for March, April and December. The poleward flow at this depth increases from July to September and then decreases till November, unlike the $100 \mathrm{~m}$ depth record (subplot d) where poleward flow intensifies from July to December. This shows that after September there is an intensification of the surface flows and a weakening at deeper levels. At the Mediterranean Water levels (subplots h) and i) - at 800 and 1194 metres depth, respectively), the data and model agree that the current is northward almost all year long, decreasing or even changing sign in November.

The comparisons with the current meters located at $40.1^{\circ}$ are represented in Fig. [5 - third column. Model and data show a reasonable comparison. For example, it is visible that after August the flow is northward for all depths, both in the model and in the observations.

The alongshore component of the modeled currents at 3-m depth and the modeled wind at 10-m height were also compared with records from two buoys (see locations as 1 and 2 in Fig. 22). The comparisons of the currents are shown in Fig. 6 (top row), and of the winds in Fig. 6 (2nd row). For buoy 2 the velocity was rotated to the axis of maximum variance (approximately alongshore). Model velocities were interpolated to the depth and location of the buoy. The comparison is better for buoy 2 (Fig. 6 top/right). In buoy 1 , 250 the model simulates stronger northward velocities in the autumn (September, October and November), and also, with smaller discrepancy, in December and January, although the seasonal cycle is approximately reproduced. The intensity of the southerly winds is also overestimated by the model on the same months, thus probably causing stronger modeled currents. However, it is also possible that the model is not reproducing the exact position of the IPC core, which could lead to differences of this order. For buoy 2 the comparison is better, and it improves when considering only the observational years compared to the 20 -year mean. This is not true for buoy 1 . The comparison with the buoys shows that the average seasonal cycle of the currents is similar in the model and the observations, although the model is producing in general stronger currents than observed. 
The comparison of the model and satellite mean January SST (Fig. 11- right) shows that the model is, in general, warmer than the observations in winter, although the spatial structure is not so different. The comparison with the buoys temperature at $3 \mathrm{~m}$ depth (Fig. 66- 3rd row) also shows that the model is warmer. The satellite SST for the buoys location is also represented in Fig. 6 (3rd row). This generalized warming in winter is probably forced by inconsistencies in the ocean-atmosphere heat fluxes. In July the model offshore SST is also warmer than the observations, although the discrepancy is only about $0.3{ }^{\circ} \mathrm{C}$ (Fig. 1 270 fact that we are using nightime Pathfinder SST. In July, the model seems to overestimate the upwelling intensity simulating colder inner-shelf waters than those obtained in the satellite mean field. It is possible that the resolution of the wind field is not sufficient to correctly represent the wind drop-off near the coast (Capet et al., 2004), and that the model winds are too strong near the coast (this is actually observed in the comparison between buoy 1 measured and modeled winds in Fig. 6 (2nd row), and the discrepancy may be larger near the coast). Stronger equatorward (negative) winds in summer increase coastal upwelling and decrease SST; on the other hand, stronger poleward (positive) winds in winter increase the intensity of the poleward shelf currents and thus increase the SST.

Finally, the salinity was also compared at $3 \mathrm{~m}$ depth (Fig. [6- bottom). The comparison of the seasonal cycle is better for the observational months than for the 20-year cycle, because there is few data available for salinity, as seen in Fig. 4. The major discrepancy occurs in Buoy 1, in December (Fig. 6 bottom/left). The seasonal cycle of the salinity at the buoy was calculated only with data from the years of 2005 and part of 2006 (Fig. 4), so this seasonal cycle is not representative of the 20-yrs average, but just of this period. Since the river outflow in our simulation is climatological, it is expected that the model does not reproduce the coastal salinity in specific years, at least in areas with the presence of river plumes. 


\section{Average seasonal cycle}

We used the 20-year model outputs to compute monthly means of the velocity fields. In this section we will show the results of the horizontal and vertical fields of horizontal velocity from the highest resolution domain (A1 in Fig. 2).

\subsection{Horizontal circulation}

In Fig. 7, we show the monthly mean fields of the depth-averaged velocities. The vertical averaging was done from the surface either to the bottom or to $350 \mathrm{~m}$ when the water column is deeper than that. This depth was chosen because previous studies show that the IPC occupies approximately the upper $350 \mathrm{~m}$ of the water column. In January, the currents over the slope and the shelf flow to the north. Between February and April the near-shore currents veered from northward to southward flow. After April, the southward upwelling jet over the shelf intensifies reaching its maximum intensity in July. In August, the jet decays and, over the slope, a weak northward flow becomes detectable. In September, this northward flow intensifies and becomes dominant though remnants of the southward upwelling jet still persist in a few places close to the coast. In October, the flow is northwards over the shelf and slope. After a decrease of the shelf and slope velocity magnitude in November, it increases again in December.

During the transition months (February and March), north of $42^{\circ} \mathrm{N}$, the time-averaged poleward flow is located further offshore. South of this latitude, there is no sign of westward propagation of the flow. The Sea Surface Height anomaly (SSHa) also exhibits a very clear signal (see the Hovmoller plot on 15 Fig. 8). A negative anomaly establishes near the coast from April till the end of September, with larger values in July and August (the months of maximum upwelling intensity). In October, the signal reverses and a positive anomaly develops near the coast, persisting till the end of March. Both summer and winter anomalies propagate offshore. We find a reasonable match between the altimetry and the model results, concerning both the seasonal cycle of the SSHa and the offshore propagation of the anomalies. 


\subsection{Vertical structure of the alongshore currents}

This section describes the seasonal variability of the alongshore currents (North-South component) for 2 control sections (sections I and II in Fig. 2 325 and (7). In order to evaluate the importance of the seasonal variability when compared to the total variability of the currents, we calculated the best fit to the meridional velocity of one sinusoid with one-year period and of another with 6month period, and computed the standard deviation of the adjusted curves. By dividing each standard deviation by the total standard deviation we estimated 330 the relative importance of these 2 components of variability. The results are plotted in Fig. 9, In both sections, over the shelf and over the slope in the upper $300 \mathrm{~m}$ of the water column, the seasonal cycle is dominant and represents more than $40 \%$ of the total variability (Fig. 9- first row). Since the inflow of the rivers is climatological in the simulation, its influence might contribute to the high relative importance of the seasonal cycle at the upper levels and close to the coast. In section II, the seasonal cycle is also relevant at deeper levels near the slope, explaining around 20 to $30 \%$ of the total variability. Different cores are present on these sections, representing areas with different relative importance of the seasonal cycle: one on the shelf, other on the upper slope/shelf break, and a third one over the slope at the Mediterranean Water levels (600 - $1200 \mathrm{~m}$ depth). Off the slope, the seasonal cycle contribution is low. In section I, the variability due to the half-year component is also relevant, explaining more than $25 \%$ of the total variability (Fig. 9- second row/left). This is related to the offshore propagation of the northward currents, shown in Fig. 7 In section

345 II, there are significant values at levels deeper than $600 \mathrm{~m}$ over the slope. The third row shows that the seasonal cycle and its first harmonic, together, explain more than $40 \%$ of the variability of both slope and shelf alongshore currents, justifying the study of their mean monthly evolution. Offshore of the slope zone these time frequencies of the alongshore velocity variability are important in section I, explaining more than $40 \%$ of the variability, but not as much in section II, where monthly (eddies) or interannual scales taken together are more 
important (not shown).

\subsubsection{Section $I-42.2^{\circ} N$}

The monthly averages of the alongshore currents (north-south component) USCC emerged in November). The IPC intensifies near the surface reaching a maximum in December, after a decrease of the intensity in the whole water column in November. The monthly evolution of the 20 -years mean indicates that the IPC starts developing in summer over the shelf break and reaches its for section I are displayed in Fig. 10. In January, there is a deep northward flow over the slope, extending from the surface down to $1200 \mathrm{~m}$ depth. The vertical structure consists of two cores of northward velocity: the surface-intensified IPC, in the upper $200 \mathrm{~m}$, and the IPSU, confined to the slope between 600 to $1200 \mathrm{~m}$ depth. At around $400 \mathrm{~m}$ depth, near the slope, a weak southward core (USCC). The shelf is occupied by a coastal poleward jet. From February to April the IPC intensity decreases, the poleward flow widens and seems to propagate offshore. The offshore propagation occurs at all depths, but it is more noticeable in the upper $800 \mathrm{~m}$ of the water column. These northward velocities propagating westward were also observed in the horizontal velocity fields of Fig. 7. Near the slope at $400 \mathrm{~m}$ depth, the USCC is visible from January to May (though less clear in February). From April to July the shelf is dominated by increasing southward flow associated with the upwelling jet. However, offshore of the jet, at the shelf break, there is still evidence of a poleward flow extending from near the surface down to more than $1200 \mathrm{~m}$ deep (more evident after June). In August and September the southward upwelling jet becomes weaker and shallower, hiding the IPC below the surface. The two cores of positive velocity become visible again: the IPC, near the shelf break at around $200 \mathrm{~m}$ depth, and the IPSU, over the slope from 600 to $1200 \mathrm{~m}$ depth. From October to December the flow is northward all over the slope and the shelf (although fully developed stage in December. 


\subsubsection{Section $I I-40.1^{\circ} \mathrm{N}$}

Fig. 11 represents the seasonal evolution of the alongshore flow in section II. The seasonal cycle is similar to that of section I, although the alongshore flows are in general weaker and more barotropic. There seems to be a weak

offshore propagation from February to April. Offshore, the main circulation is southward almost all year long, except from February to April. In this section, in September and October, the slope poleward flows are vertically coherent and there is no distinction of the IPSU core. This means that the current on these months is more barotropic in section II than on section I, where the presence of two cores is visible almost along the entire year. The IPC maximum is also, as in section I, in December and January, but the maximum intensity is not at the surface but at around $100 \mathrm{~m}$ depth.

\subsubsection{Meridional transports}

To summarize the information about the alongshore flows, we computed the model meridional transport for sections I and II. Each section was divided in 3 areas according to their dynamical properties (these areas are shown in Figures 10 and 11. for sections I and II, respectively). The areas are named: Upper Slope (A) - that corresponds to the region over the slope and shelf break, from the surface to 350 metres deep, enclosing the IPC core; the Deep Slope (B) - that is the region over the slope, from 350 to 1200 metres deep, containing the IPSU core; and the Shelf $(\mathrm{C})$ - that contains all the water column over the shelf. The transports for each area and section are presented in Fig. 12. Since the areas where the transports were computed are different in the two sections (because the bathymetry is different), the absolute values are not directly comparable between each other. The idea here is to systematize the results for each section and to compare the seasonal cycles of the 2 sections. We separated northward and southward transports, by computing only northward or southward velocities across the areas.

Fig. 12 (A) shows northward and southward transports across the Upper Slope area. The area encloses the IPC, both the surface intensified December- 
January core and the shelf break core, present by the end of the upwelling season. The seasonal cycle of the northward transport shows two maxima, one in December-January and the other in September-October. The seasonal cycle is similar in both sections. In section I (northernmost one) there is a greater intensification of the northward transport in the period from December to February.

Fig. 12 (B) shows the transport across the Deep Slope area. The northward transport for the 2 sections also presents 2 maxima. The maxima are in February (higher in section I) and in September for both sections, not totally in phase with the surface ones (Fig. 12(A)). They are lagging the surface winter peak by one month and anticipating the autumn peak by one month. The net transport is northward almost all year long in both sections.

The total net transport (sum of deep slope transport with upper slope transport) averaged between the 2 sections, is represented in Fig. 12 (B). It shows ${ }_{425} 2$ maxima, one in September, with an average transport of $1.23 \mathrm{~Sv}$ and the other in February, with an average of $1.17 \mathrm{~Sv}$. The lowest transport values are observed in April, May and November.

Finally, the shelf area is represented in Fig. $12(\mathrm{C})$. The dominant transport during the summer is to the south, coincident with summer upwelling and the associated southward jet. The southward transport is significant from March to September and reaches a maximum in July, of about $0.11 \mathrm{~Sv}$. There are no significant differences between the 2 sections. From September to January the net transport over the shelf is to the north, and stronger on section I. There are several processes contributing to the northward transport over the shelf: currents induced by the river plumes (which are more frequent in winter), southerly wind episodes and the penetration of the slope northward current into the outer shelf.

\subsection{Temperature and Salinity}

Figures 13 and 14 show the average vertical section of alongshore velocities together with temperature for sections I and II (Fig. 2), respectively. In both 
sections, the downward tilting of the isotherms towards the upper slope, visible from October to March, suggests the importance of the IPC in transporting heat northwards. From June to September the shelf is occupied by colder waters that upwell from deeper levels, as it is visible by the outcrop of the isotherms near the coast. There is a clear seasonal cycle of the vertical stratification: from December to April the mixed layer is deeper, reaching a maximum of almost $200 \mathrm{~m}$ depth in March. In Summer, stratification increases due to surface warming. Section II is generally warmer than section I, but the seasonal cycle is similar in both sections.

Monthly averaged salinity sections are presented in figures 15 and 16, for sections I and II, respectively. The salinity maximum over the upper slope from September to February is approximately coincident with the IPC core (Figures [15] and (16), revealing the IPC role in poleward salt transport. The river plumes characterized by the low salinity values are confined, from October to January, to the region near the coast due to the recurrent southerly wind episodes that force convergence of the surface waters onshore. From March to June the plumes extend further offshore coinciding with the onset of the northerly winds.

\subsubsection{Heat and Salt Budgets}

In order to understand the different factors forcing the seasonal cycle of salinity and temperature, we computed the heat and salt budgets average seasonal cycle in the top $200 \mathrm{~m}$ of the water column using the equations 1 and 2 A similar calculation was done in Wilkin (2006) and Colas et al. (2012) for heat fluxes, and in Qu et al. (2011) and Gao et al. (2014) for salinity fluxes.

$$
\begin{aligned}
\int_{z_{0}}^{\eta} \rho_{0} C_{p} \frac{\partial T}{\partial t} d z= & -\int_{z_{0}}^{\eta} \rho_{0} C_{p} \vec{v} \cdot \vec{\nabla} T d z+Q_{a t m}+ \\
& +\int_{z_{0}}^{\eta} \rho_{0} C_{p} D h_{T} d z-\left.\rho_{0} C_{p} \kappa_{v} \frac{\partial T}{\partial z}\right|_{z_{0}} \\
Q_{a t m}= & \text { HFsen }+ \text { HFlat }+ \text { radSW }- \text { radLW }
\end{aligned}
$$




$$
\begin{aligned}
\int_{z_{0}}^{\eta} \frac{\partial S}{\partial t} d z & =-\int_{z_{0}}^{\eta} \vec{v} \cdot \vec{\nabla} S d z+S_{\text {forc }}+\int_{z_{0}}^{\eta} D h_{S} d z-\left.\kappa_{v} \frac{\partial S}{\partial z}\right|_{z_{0}} \\
S_{\text {forc }} & =S(E-P)
\end{aligned}
$$

In both equations, the term on the left side refers to the time rate (of temis deeper than $200 \mathrm{~m}$. Most of the time, the mixing terms are negligible when compared to the other terms, and the equations simplify to Eq. 3 ,

$$
\begin{aligned}
& \frac{\partial Q}{\partial t}=-a d v(Q)+Q_{a t m} \\
& \frac{\partial S}{\partial t}=-a d v(S)+S_{\text {forc }}
\end{aligned}
$$

Qatm is the total atmospheric forcing that includes: the sensible heat flux (HFsen); the latent heat flux of evaporation (HFlat), the shortwave incident radiation (radSW) including the penetrating short wave radiation; and the outgoing long wave radiation (radLW). Sforc is the atmospheric fresh water forcing corresponding to evaporation minus precipitation multiplied by the surface salinity.

Figure 17 shows the horizontal fields of the budgets averaged for specific months (over the entire period of 1989 to 2008), and integrated in the top $200 \mathrm{~m}$ of the water column. The figure shows time rate, advection and atmospheric forcing for the months of April, July, October and December, for both heat and salinity budgets. These months were chosen to represent the most important phases of the average seasonal cycle. In April, the layer is warming in most of 
the domain $(\partial Q / \partial t>0)$ in response to atmospheric heat fluxes (Qatm). In July, the offshore region is warming while the coastal zone is cooling. The average temperature decrease along the coast is forced by vertical and/or horizontal advection; either by the upwelling of subsurface colder waters, or by the southward flowing cold jet. The atmosphere warms the entire domain especially near the coast, due to higher air-sea temperature differences that drive stronger sensible heat fluxes. In October, the situation is the opposite: the atmosphere cools the entire domain $($ Qatm $<0)$ while advection of warmer waters from the south by the IPC contributes to a temperature increase of the shelf/slope region. In December, the situation is similar but with lower advection, and stronger heat loss, contributing to a warming of the slope waters but at a much slower rate.

To compare the seasonal evolution of the heat budgets with the volume averaged temperature on the top $200 \mathrm{~m}$ of box W (see Fig. 17), as presented in Fig. 18 (a), we integrated the heat budgets in the domain and represent the quantities in Fig. 18 (c). The volume averaged temperature (Fig. 18 a) is different from the seasonal cycle of the SST (represented on the same plot). The SST maximum is in August, while the volume averaged temperature has its maximum in October, suggesting a contribution of the IPC. The heat budgets plot (Fig. $18 \mathrm{c}$ ) shows the time rate, advection, and forcing. The sum of advection and forcing is almost coincident with the average heat rate (not shown) confirming that the sum of these contributions drives the seasonal cycle of the heat rate and that the mixing terms are negligible. The atmospheric heat fluxes are positive from March to September, warming the upper layer, but they are partly compensated by advection. In July, advection balances the atmospheric heat input. After September, the IPC brings warmer waters (positive advection) to the domain $\mathrm{W}$, compensating the otherwise cooling tendency. The interplay between advection and atmospheric fluxes explains the temperature seasonal cycle on the west coast (Fig. 18 c), and its difference from the SST cycle which is more influenced by the atmospheric fluxes.

In the salinity budgets, advection controls the spatial structure of the salt rate for the various months (Fig. 17 b). In October and December, the salinity 
increases over the slope by advection. The atmospheric forcing (E-P) is positive in July, because evaporation exceeds precipitation, while in the other months precipitation exceeds evaporation north of $40^{\circ} \mathrm{N}$. The seasonal cycle of the volume averaged salinity (in the top $200 \mathrm{~m}$ of domain W) is represented in Fig. 18 b). It is similar to that of the northward transport (Fig. 12- a), suggesting that IPC is important in driving the salinity maximum season between November and March. The seasonal cycle of the salinity budgets on the domain W (Fig. 18 d) confirm that advection dominates the seasonal cycle, increasing salinity in September, October and December, and decreasing it from January to July

${ }_{525}$ (Fig. $18 \mathrm{~d}$ ). This means that the winter circulation, dominated by the IPC, is of major importance for the poleward salt transport.

\section{Seasonal forcing of the slope region}

\subsection{Depth-averaged vorticity equation}

In order to understand which mechanisms force the Iberian Poleward Current and what are the processes driving its seasonal variability, we computed the vorticity balances in the slope zone. Starting from the horizontal momentum equations with the Boussinesq approximation, the equations for the zonal and meridional velocities $(\mathrm{u}, \mathrm{v})$ are:

$$
\begin{aligned}
& \frac{D u}{D t}=f v-\frac{1}{\rho_{0}} \frac{\partial p}{\partial x}+\frac{1}{\rho_{0}} \frac{\partial \tau^{x}}{\partial z} \\
& \frac{D v}{D t}=-f u-\frac{1}{\rho_{0}} \frac{\partial p}{\partial y}+\frac{1}{\rho_{0}} \frac{\partial \tau^{y}}{\partial z}
\end{aligned}
$$

Taking the depth average of the set of equations 4 and then cross differentiating and rearranging the terms, we obtain a vorticity $(\hat{\xi})$ equation for the depthaveraged flow :

$$
\begin{aligned}
\beta \bar{v}= & -\hat{\xi}_{t}+\frac{f}{H}\left[\bar{u} \frac{\partial H}{\partial x}+\bar{v} \frac{\partial H}{\partial y}\right]+J\left(\chi, H^{-1}\right) \\
& +\frac{1}{\rho_{0} H}\left[\frac{1}{H}\left(\frac{\partial H}{\partial y} \tau_{x}^{w}-\frac{\partial H}{\partial x} \tau_{y}^{w}\right)\right]
\end{aligned}
$$




$$
\begin{aligned}
& +\frac{1}{\rho_{0} H} \vec{\nabla}_{h} \times \tau^{w}-\vec{\nabla}_{h} \times \overline{a d v} \\
& -\left[\frac{1}{\rho_{0} H} \vec{\nabla}_{h} \times \tau^{b}+\left[\frac{1}{H}\left(\frac{\partial H}{\partial y} \tau_{x}^{b}-\frac{\partial H}{\partial x} \tau_{y}^{b}\right)\right]\right]
\end{aligned}
$$

where $\left(\vec{\nabla}_{h} \times\right)$ is the vertical component of the curl $(\hat{k} . \vec{\nabla} \times)$, adv are the advective terms, $\mathrm{J}$ is the Jacobian operator, $\tau^{w}$ is the wind stress, $\tau^{b}$ the bottom stress, the overbars represent vertical average, the subscript t (e.g. $\hat{\xi}_{t}$ ) stands for time derivative, $\eta$ is the surface elevation, $\mathrm{H}$ is bottom depth,

$$
\begin{gathered}
\hat{\xi}=\frac{\partial \bar{v}}{\partial x}-\frac{\partial \bar{u}}{\partial y} \\
(\bar{u}, \bar{v})=\frac{1}{H} \int_{-H}^{\eta}(u, v) d z \\
\chi=\frac{g}{\rho_{0}} \int_{-H}^{\eta} z \rho d z \\
\vec{\nabla}_{h} \times \overline{a d v}=\frac{\partial}{\partial x}\left[\frac{1}{H} \int_{-H}^{\eta}\left(u \frac{\partial v}{\partial x}+v \frac{\partial v}{\partial y}\right) d z\right] \\
-\frac{\partial}{\partial y}\left[\frac{1}{H} \int_{-H}^{\eta}\left(u \frac{\partial u}{\partial x}+v \frac{\partial u}{\partial y}\right) d z\right]
\end{gathered}
$$

The same procedure was followed in Guo et al. (2003), Mertz and Wright (1992), Huthnance (1984) and Lee et al. (2001). Couvelard et al. (2008) and Holland (1973) obtained the vorticity equation by taking the curl of the depthintegrated (instead of the depth-averaged) momentum equations. Following this alternative procedure, different terms are obtained, but the results are compatible as demonstrated in Mertz and Wright (1992).

We used equation 5 to understand how do the various terms interplay to force a meridional depth averaged slope flow $(\beta \bar{v})$. The terms in equation 5 represent:

1. Vbeta: the planetary vorticity advection $(\beta \bar{v})$;

2. Vrate: the rate of change of relative vorticity of the depth-averaged flow $\left(-\hat{\xi}_{t}\right)$ 
3. Stretching: the topographic vortex stretching $\left(\frac{f}{H}\left[\bar{u} \frac{\partial H}{\partial x}+\bar{v} \frac{\partial H}{\partial y}\right]\right)$. In an idealized situation of the Iberian Western Coast, with a meridionally oriented slope $\left(\left(\frac{\partial H}{\partial y}\right)=0\right)$ and a meridionally oriented wind stress $\left(\tau_{x}^{w}=0\right)$, since $\partial H / \partial x<0$, the sign of the stretching term depends on the sign of the depth-averaged cross isobath flow $\bar{u}$. For example in the case of an inviscid barotropic flow, an eastward cross-isobath flow would cause water column compression and reduction of total vorticity;

4. JEBAR: the Joint Effect of Baroclinicity and Relief $\left(J\left(\chi, H^{-1}\right)\right)$ (Huthnance, 1984) representing the effect of the density field in the depth-averaged current. In the idealized case of a meridional coast line $\left(\left(\frac{\partial H}{\partial y}\right)=0\right)$, in the presence of a positive meridional density gradient, JEBAR reduces to $+\frac{g}{\rho_{0} H^{2}} \frac{\partial H}{\partial x} \frac{\partial}{\partial y}\left[\int_{-H}^{\eta} z \rho d z\right]$. In this case JEBAR will act as a positive contribution to the planetary vorticity term (note that $\mathrm{z}$ is negative), resulting in northward flow in a stationary state;

5. WindSIT: the wind slope induced torque $\left(\frac{1}{\rho_{0} H}\left[\frac{1}{H}\left(\frac{\partial H}{\partial y} \tau_{x}^{w}-\frac{\partial H}{\partial x} \tau_{y}^{w}\right)\right]\right)$ is related to the different responses experienced by different thickness water columns when subjected to a constant wind stress. In the idealized case $\left(\left(\frac{\partial H}{\partial y}\right)=0\right.$ and $\left.\tau_{x}^{w}=0\right)$, the variability of this term is only dependent on the alongshore component of the wind stress. A positive $\tau_{y}^{w}$ (southerly winds) will result in WindSIT giving a positive contribution to the poleward flow;

6. WSCurl: the wind stress $\operatorname{curl}\left(\frac{1}{\rho_{0} H} \vec{\nabla}_{h} \times \tau^{w}\right)$;

7. TAdvec: the curl of the depth-averaged advection terms $\left(-\vec{\nabla}_{h} \times \overline{a d v}\right)$;

8. BottomS: the total effect of bottom friction $\left(-\left[\frac{1}{\rho_{0} H} \vec{\nabla}_{h} \times \tau^{b}+\left[\frac{1}{H}\left(\frac{\partial H}{\partial y} \tau_{x}^{b}-\frac{\partial H}{\partial x} \tau_{y}^{b}\right)\right]\right]\right)$, that includes the bottom stress curl and the bottom slope induced torque (the bottom slope induced torque was introduced by Lee et al. (2001)) and is related to the effect that a constant bottom stress will exert on different thickness water columns.

The momentum terms of the set of equations 4 were computed and stored during the model simulation so that the vorticity equation is balanced. We 


\begin{tabular}{lr}
\hline VTERM & GlobAVG \\
\hline VBeta $=$ & 0.33 \\
-Vrate & 0.002 \\
+ Stretching & -6.00 \\
+ JEBAR & 9.94 \\
+ WindSIT & -2.75 \\
+ WSCurl & 0.84 \\
+ TAdvec & 0.94 \\
+ BottomS & -2.64 \\
\hline
\end{tabular}

Table 1: Global time average of area-integrated values of all terms in equation $5\left(m^{2} s^{-2}\right)$ terms are multiplied by $10^{12}$. The area of integration is shown in Fig. 2 by the cyan line in the zoom plot.

computed the vorticity budgets and then horizontally integrated over the slope area between $40-43^{\circ} \mathrm{N}$ and between the isobaths of 200 and 1200 metres (area of integration is shown in cyan in the right plot of Fig. 21).

\subsection{Time-mean balance}

Table 1 presents the area-integrated and time-averaged terms of the vorticity equation. Vrate is negligible due to the long averaging period. The terms on the right side of the vorticity equation 5 can be evaluated for their contribution to the mean meridional transport (VBeta). VBeta is positive since the depthaveraged meridional velocity is poleward almost all year long. JEBAR is by far the dominant forcing term and together with WSCurl and TAdvec, these are the only terms that give average positive contributions to the poleward flow (although the latter two are much smaller). The other terms compensate this positive contribution (essentially of JEBAR): Stretching, WindSIT and BottomS. Although these terms differ in magnitude, none of them is negligible, suggesting a complex interaction between the various forcings on the slope. 


\subsection{Seasonal cycle of integrated vorticity terms}

The seasonal evolution of the area integrated (area in Fig. 2) monthlyaveraged terms of the vorticity equation (5) is presented in Fig. 19, A similar procedure was taken by Guo et al. (2003).

Vbeta (Fig. 19 a) is high in January and February, then it decreases to nearly zero from April to July (with a weak inversion to southward flow in April and in July). In July, Vbeta starts to increase reaching a first peak in September/October and the maximum in December, after a small decrease in November. The seasonal cycle is similar to that of the net transport (dasheddotted line on Fig. (12).

The contribution of the different terms to the monthly balance (Fig. 19 b) has been analyzed in search for the main contributors to the seasonal cycle of the Vbeta term. It is not possible to establish cause-effect relationships between VBeta and changes in the forcings (JEBAR, WindSIT, Stretching, BottomS, WSCurl), because Vrate and TAdvec are not negligible. Nevertheless, the latter terms are much smaller than the larger amplitude forcing terms, making it possible to analyze the relative role of the various forcing terms. JEBAR is on average the strongest term almost year long, reaching a maximum in the summer and decreasing in winter, when the poleward flow reaches its maximum intensity. During the period from August to January, the poleward flow changes to a surface intensified current (as shown in Figures 10 and 11 and discussed in subsection 3.2). The main contribution in August is from JEBAR. WindSIT, Stretching and BottomS are negative, but do not balance the positive contribution of JEBAR, suggesting that the deep poleward flow in August is mainly driven by JEBAR. JEBAR decreases from August to January, when its value is close to zero. On the other hand, WindSIT increases, turning positive in October and reaching maximum intensity in January. In December the poleward flow reaches maximum intensity and the jet is strongly intensified near the surface (Fig. 10 and 11). In the vorticity balance the main positive contribution in December is of WindSIT, suggesting that it is the term responsible for that December-January surface intensified maximum. Note, however, that the 

with the velocity).

To summarize, the relative role of each term in the vorticity balance varies from month to month. Nevertheless, JEBAR guarantees the major contribution to the poleward flow, as it is the largest positive term, and it explains the exis-

contribution of stretching and TAdvec cannot be ruled out (BottomS co-varies tence of poleward flows almost all year long, including the summer months. In December-January, when the IPC reaches maximum intensity near the surface, the main contribution is of WindSIT. WindSIT variability depends on the alongshore component of the wind stress which is on average positive (southerly) from October to January, reaching a maximum of intensity in December-January.

4.4. Cross-shore structure of alongshore flow

It was shown above that the alongshore flow presents a clear vertical structure that also varies from month to month. The vorticity balances are applied to vertically integrated flow and therefore cannot explain the vertical structure. However, together with the vertical structure, the flow also displays a clear cross-shore variability. The cross-shore structure of the vorticity equation terms was computed in order to search for relations with the main cores of the alongshore flows: IPC, IPSU and USCC. We averaged the vorticity terms along each isobath from 40 to $43^{\circ} \mathrm{N}$. The terms for selected months are plotted as function of depth (Fig. 20 $2^{\text {nd }}$ and $3^{\text {rd }}$ rows). The figure also shows the alongshore velocity sections, as function of depth too (Fig. 20- $1^{\text {st }}$ row). We focus on the months of August to December, the period of intensification of the IPC.

The IPC core is located in the upper $350 \mathrm{~m}$ of the water column, approximately between the isobaths of 100 and $500 \mathrm{~m}$ (see velocity sections on the $1^{\text {st }}$ row of Fig. 201). In August, JEBAR is maximum and is the main term forcing the IPC, compensated in part by WindSIT, stretching and BottomS (see $2^{\text {nd }}$ row of Fig. 201). Advection terms are important at the core of the IPC with a maximum over the $250 \mathrm{~m}$ isobath. Note that WSCurl starts becoming more important over the shelf. From August to October, WindSIT changes from negative to positive, explaining the intensification of the IPC. The total forcing over 

ber, the total forcing decreases substantially (due to a decrease in both JEBAR and WindSIT) resulting in a relative weakening of the IPC. In December, the IPC reaches the maximum intensity in response to WindSIT and Advection terms (that are maximum at the core while JEBAR becomes negative). located approximately between the isobaths 500 and $1200 \mathrm{~m}$. In general, JEBAR is weaker at these depths, due to its dependence on $1 / \mathrm{H}^{2}$ but it is still the dominant positive term, suggesting that it may be the forcing mechanism for the IPSU. It increases in September timely with the intensification of the IPSU, and then decreases in October and November, when IPSU reaches a minimum. In December, JEBAR increases slightly again and WindSIT becomes positive, coincident with an increase in IPSU intensity.

The JEBAR minimum in December/January, discussed in the previous section, is limited to the upper $500 \mathrm{~m}$ of the slope, since over the deeper slope the changes are much weaker and the JEBAR maximum is in December (Fig. 20]$2^{\text {nd }}$ row).

The cross-shelf analysis of the terms does not help in explaining the USCC because it is located under the IPC which is much more intense. To understand its seasonality we computed the geostrophic flow structure from the density average field using the thermal wind equation. The thermal wind equation was integrated from the surface using a surface geostrophic velocity obtained from the sea surface height gradient. This estimate is shown for section I in Fig. $21-2^{\text {nd }}$ row. There is a good match between the geostrophic velocity sections and the mean absolute velocity sections (Fig. 21- $1^{\text {st }}$ row), suggesting that the velocity structure can be explained by the evolution of the internal density field. The USCC is visible in November and January, both in the mean meridional velocity section and in the velocity fields obtained from the density structure (the core of USCC extends vertically from approximately $250 \mathrm{~m}$ to $500 \mathrm{~m}$ depth). ${ }_{680}$ On the top $350 \mathrm{~m}$ of the water column, the cross-shore density gradient $\partial \rho / \partial x$ 
is mainly negative (e.g. $4^{\text {th }}$ row January plot on Fig. 21), because the IPC advects less dense water northwards over the slope. This density gradient forces a decrease of the meridional geostrophic velocity in depth, which eventually becomes negative. This is probably the reason why a southward current (the

\section{Discussion}

Our results confirm the existence of a seasonal cycle of the alongshore flows and present new information regarding its vertical structure, forcing and relation with temperature and salinity seasonal cycles. Poleward flows are present 
discussion we present a scheme of the seasonal cycle of the alongshore flows in Fig. 23. The figure summarizes the main features of the sections I and II (Figures 10 and 11). The IPC starts developing near the shelf break at around $200 \mathrm{~m}$ depth (Fig. 23 - August). After September, the IPC core becomes a surface intensified jet north of $41^{\circ} \mathrm{N}$ (Fig. 23 September-November). South of that latitude the maximum is never shallower than $100 \mathrm{~m}$ depth yearlong. In December and January, the IPC reaches its maximum expression as a narrow and intense poleward flow in the upper $350 \mathrm{~m}$ of the water column. At deeper levels, the IPSU core extends on average from 600 to $1200 \mathrm{~m}$ depth, and is present almost also confirms that IPC intensifies near the surface, from September to December, and that IPSU is minimum in November. Our description of the vertical structure and seasonal cycle is in agreement with previous studies:

1. The existence of two cores of poleward flow (IPC and IPSU - Fig. 23) was first suggested in Ambar and Fiúza (1994), that analyzed part of the current meter data set used in this paper. IPSU is described in Daniault et al. (1994).

2. The surface intensified core (IPC) in the winter months (see Fig. 23 December/January) was first observed by Frouin et al. (1990) and was further studied for its conspicuous SST signature (Pingree and Le Cann, 1990, 1992b; Peliz et al., 2005; Garcia-Soto and Pingree, 2011).

3. The IPC intensification near the shelf break, at around $200 \mathrm{~m}$ depth, during the upwelling season (see Fig. 23 - August), was observed by Peliz et al. (2002), who presented hydrology observations from a section 
at $41^{\circ} \mathrm{N}$ (our section II) in September 1998. Under upwelling conditions over the shelf, they observed the presence of a higher salinity anomaly over the upper slope, with a subsurface maximum of salinity at around $80 \mathrm{~m}$ depth, indicating a poleward flow located just offshore/below the upwelling jet, similar to the near surface vertical structure we see in our results (Fig. 23 - August). Llope et al. (2006) also observed a doublecore vertical structure of salinity in the Bay of Biscay, in January of 1999 and 2002, with two maxima of water intruding from the west coast. The deeper core is at the depths of the shelf break, suggesting that an intensified poleward current was present at or just before the observations. Le Cann and Serpette (2009) in a study of the Bay of Biscay (northern margin) in the autumn of 2006, also observed the presence of saline waters (originated off the western Iberia margin) confined to the upper slope (shelf break), not reaching the surface.

4. The presence of the USCC at around $400 \mathrm{~m}$ depth (see Fig. 23 - December to April), was observed by Oliveira et al. (2004), in geostrophic velocity sections computed from temperature and salinity field observations at $41.3^{\circ} \mathrm{N}$, on February 2000. The equatorward flow also appears in other numerical modeling studies (Peliz et al., 2003b; Friocourt et al., 2007, 2008b).

5. The weakening of IPSU in the wintertime (with minimum alongshore velocity in November) is consistent with the results from Prieto et al. (2013). They collected semiannual hydrological data from a section at $43^{\circ} \mathrm{N}$ from 2003 to 2010 and concluded that the Mediterranean Water vein is stronger and attached to the slope in the summer, while in winter it spreads offshore.

It was confirmed that the IPC has an important role in driving the seasonal cycle of temperature and salinity in the upper $200 \mathrm{~m}$ of the shelf and slope. In the case of salinity, the advection terms dominate the salinity budgets seasonal cycle, showing that the seasonal cycle of salinity is mainly controlled by the IPC. These 
results support Llope et al. (2006) results for the northern coast; they analyzed monthly series of CTD samplings from 1993 to 2003 and observed intrusions of Eastern North Atlantic Central Waters of subtropical origin (ENACWst) in the Northern Iberia almost every winter, which suggested the important role of the IPC in driving the average temperature and salinity seasonal cycles on the northern coast. We verified that the seasonal cycle of the temperature is forced by both the circulation (IPC and upwelling) and by local air-sea fluxes.

The vorticity balances over the slope confirm that JEBAR is on average the strongest term almost year long. Its contribution is higher in summer than in winter, but the cross-shore analysis shows that JEBAR decreases substantially at the core of the IPC, where the advection terms become relevant. Offshore, the meridional density gradients at the IPC depths are more intense in winter, reaching a maximum in December/January (not shown) as already suggested in Peliz et al. (2005). The co-variation of JEBAR and wind forcing over the slope suggests that wind forcing modifies the meridional density gradient near the coast. It forces northward density advection and diminishes JEBAR by eroding the meridional density gradients. In December and January, the strongest positive term is the windSIT (southerly wind forcing). There is also an important negative contribution from the Stretching term, that is negative all year long and stronger in December and January, and from the Bottom Stress, which is also negative all year long and co-varies with the velocity (Vbeta). The contribution of the different terms to the monthly balance (Fig. 19] b) has been analyzed in search for the main contributors to the seasonal cycle of the Vbeta term, but the Bottom Stress term also includes the alongshore velocity and is larger than Vbeta. So it is possible to think of a balance between the different forcing terms and BottomS, which also co-varies with the velocity.

The vorticity balances analysis show that in December and January the main contribution to the IPC is from the southerly wind forcing (windSIT), which is in agreement with the studies of Le Cann and Serpette (2009) and Garcia-Soto and Pingree (2011). The former describes a surface intensified IPC event (with strong thermal signal) in the autumn-winter 2006-2007 that hap- 
pened during intense southerly winds. The latter shows that events of anomalous high sea surface temperature in winter, on the west coast at $42^{\circ} \mathrm{N}$, occur under the presence of southerly winds. In August, the IPC core is intensified near the shelf break (and not at the surface) because of the presence of opposing northerly winds (negative WindSIT in Fig. 19), that drive the southward upwelling jet. After September, the meridional wind stress becomes positive allowing the IPC core to surface. Peliz et al. (2003a) present an idealized experiment to study the response of a slope density-driven poleward current to wind forcing. They verified that a well established poleward surface current under the action of northerly winds, diminishes its intensity and the core is displaced offshore, but it does not become an undercurrent. In our results the northerly winds are already set, when the JEBAR term becomes significant. For that reason the IPC starts developing as an undercurrent, near the shelf break.

At the IPC core, the advection of vorticity becomes important, as well as the advection of temperature and salinity, and consequently of density (in the presence of a meridional density gradient). As shown in Fig. 22, there is a strong large scale positive meridional density gradient, in the upper $400 \mathrm{~m}$ of the water column. This means that advection of less dense waters from the south to the north over the slope, will result in the onset of a negative cross820 shore density gradient, that by thermal wind produces a positive vertical shear of the meridional velocity. Consequently, the IPC will decrease with depth and eventually become negative. This process should explain the existence of an equatorward current, the USCC, under the IPC core. Peliz et al. (2003b) and Peliz et al. (2003a), forced a slope current with a meridional density gradient

825 (JEBAR) in a two layer density structure and also obtained an equatorward flow under the surface poleward current.

The large scale meridional density gradient becomes negative from $400 \mathrm{~m}$ to around $900 \mathrm{~m}$ depth (Fig. 22). The presence of a positive cross-shore density gradient at these depths (see Fig. 21 last row) indicate that IPSU advects this anomaly northward, along the Iberian slope. These meridional gradients of alternating signs were already described by Friocourt et al. (2008b). They 
impose these meridional density gradients in a four layer density structure in analytical and idealized numerical studies and obtain a four-layer slope current system, with alternating positive and negative velocities between consecutive layers.

\section{Summary and conclusions}

We use a high resolution realistic numerical model to study the average seasonal variability of the alongshore currents in Western Iberia. We show that the average alongshore current over the slope is organized in 3 different cores.

${ }_{840}$ The Iberian Poleward Current (IPC), occupying the top $350 \mathrm{~m}$, the Upper Slope Countercurrent (USCC), equatorward and centered at around $400 \mathrm{~m}$ depth and the Iberian Poleward Slope Undercurrent (IPSU), that extends from around $600 \mathrm{~m}$ to $1200 \mathrm{~m}$ depth (coincident with the northward along-shore path of the Mediterranean Water vein). The IPC starts developing near the shelf break at around $200 \mathrm{~m}$ depth still during the summer months, when the shelf and upper slope is occupied by southward flow associated with the upwelling. At the end of the year (December and January), the average meridional wind changes direction from northerly to southerly. This together with an increase of the river outflow, force poleward flow over the shelf. During these months, under favorable wind conditions, the IPC core migrates vertically, from the shelf break depths to the surface, becoming a surface intensified jet. From February to May, the current weakens and part of it propagates offshore. We confirm that IPC has an important role in driving the seasonal cycle of temperature and salinity on the Iberian western coast. Analysis of the barotropic vorticity equation on the slope showed that JEBAR is the most important forcing mechanism of the slope current, as it is the largest positive term in the vorticity equation. However, as advection terms become important, the northward density flux diminishes the meridional density gradients, resulting in a decrease of JEBAR at the core of the IPC. In December and January, southerly winds are the major contribution for the northward flows, dominated by a strong surface intensified 
IPC. It is important to note that these results refer to average conditions, that filter mesoscale and interannual variability, so the currents actually observed on a particular month and year might be completely opposite from the mean.

\section{Acknowledgement}

This study had the support of the Portuguese Science Foundation (FCT) (MedEx (MARINERA/MAR/0002/2008), Sflux (PTDC/MAR/100677/2008), Pest-Oe/CTE/LA0019/2013/2014, and UID/GEO/50019/2013), and of the Office of Naval Research (grant N00014-12-1-0939). ATM was funded with the grants SFRH/BD/40142/2007 and SFRH/BPD/100720/2014, by the FCT. ATM acknowledges UCLA (University of California Los Angeles) for the hospitality during her visit to the Oceanic Research Group. We thank the anonymous reviewers for constructive comments on the manuscript.

\section{References}

Ambar, I., 1985. Seis meses de medições de correntes, temperatura e salinidade na vertente continental Portuguesa a $40^{\circ} \mathrm{N}$. Technical Report. Dep. Fisica, Centro de Geofísica, Universidade de Lisboa.

Ambar, I., Fiúza, A., 1994. Some features of the Portugal Current System: a poleward slope undercurrent, an upwelling-related summer southward flow and an autumn-winter poleward coastal surface current, in: Proceedings of the Second International Conference on Air-Sea Interaction and on Meteorology and Oceanography of the Coastal Zone, pp. 286-287.

Antonov, J., Locarnini, R., Boyer, T., Mishonov, A., Garcia, H., 2006. World Ocean Atlas 2005 Volume 2: Salinity. U.S. Government Printing Office, Washington, D.C.

Beckmann, A., Haidvogel, D.B., 1993. Numerical Simulation of Flow around a Tall Isolated Seamount. Part I: Problem Formulation and 
Model Accuracy. Journal of Physical Oceanography 23, 1736-1753. doi $10.1175 / 1520-0485(1993) 023<1736$ : NSOFAA $>2.0 . C 0 ; 2$

Capet, X., Marchesiello, P., McWilliams, J.C., 2004. Upwelling response to coastal wind profiles. Geophysical Research Letters 31, L13311.

Casey, K., Brandon, T., Cornillon, P., Evans, R., 2010. The Past, Present and Future of the AVHRR Pathfinder SST Program, in: Barale, V., Gower, J., Alberotanza, L. (Eds.), Oceanography from Space: Revisited. Springer Netherlands, pp. 273-287.

Chainho, P., Costa, J., Chaves, M., Lane, M., Dauer, D., Costa, M., 2006. Seasonal and spatial patterns of distribution of subtidal benthic invertebrate communities in the Mondego River, Portugal - a poikilohaline estuary. Hydrobiologia $74,555-559$.

Colas, F., McWilliams, J.C., Capet, X., Kurian, J., 2012. Heat balance and eddies in the Peru-Chile current system. Climate Dynamics 39, 509-529.

Couvelard, X., Marchesiello, P., Gordeau, L., Lefevre, J., 2008. Barotropic Zonal Jets Induced by Islands in the Southwest Pacific. Journal of Physical Oceanography 38, 2185-2204.

da Silva, A., Young, A.C., Levitus, S., 1994. Atlas of Surface Marine Data 1994, Volume 1: Algorithms and Procedures. NOAA Atlas NESDIS 6. U.S. Department of Commerce. Washington, D.C.

Daniault, N., Mazé, J., Arhan, M., 1994. Circulation and mixing of Mediterranean Water west of the Iberian Peninsula. Deep-Sea Research 41, 16851714.

910

Debreu, L., Marchesiello, P., Penven, P., Gambon, G., 2012. Two-way nesting in split-explicit ocean models: algorithms, implementation and validation. Ocean Modelling 49-50, 1-21. 
Fairall, C., Bradley, E., Rogers, D., Edson, J., Young, G., 1996. Bulk parameterization of air-sea fluxes for Tropical Ocean - Global Atmosphere CoupledOcean Atmosphere Response Experiment. Journal of Geophysical Research $101,3747-3764$.

Friocourt, Y., Blanke, B., Drijfhout, S., Speich, S., 2008a. On the Dynamics of the Slope Current System along the West European Margin. Part II: Analytical Calculations and Numerical Simulations with Seasonal Forcing. Journal of Physical Oceanography 38, 2619-2638.

Friocourt, Y., Drijfhout, S., Blanke, B., 2008b. On the Dynamics of the Slope Current System along the West European Margin. Part I: Analytical Calculations and Numerical Simulations with Steady-State Forcing. Journal of Physical Oceanography 38, 2597-2618.

925 Friocourt, Y., Levier, B., Speich, S., Blanke, B. Drijfhout, S., 2007. A regional numerical ocean model of the circulation in the Bay of Biscay. Journal of Geophysical Research 112, C09008.

Frouin, R., Fiúza, A., Ambar, I., Boyd, T., 1990. Observations of a poleward surface current off the coasts of Portugal and Spain during winter. Journal of Geophysical Research 95, 679-691.

Gao, S., Qu, T., Nie, X., 2014. Mixed layer salinity budget in the tropical Pacific Ocean estimated by a global GCM. Journal of Geophysical Research 119, 1-16. Doi:10.1002/2014JC010336.

Garcia-Soto, C., Pingree, R., 2011. Atlantic Multidecadal Oscillation (AMO) and sea surface temperature in the Bay of Biscay and adjacent regions. Journal of the Marine Biological Association of the United Kingdom 92, 213-234.

Guo, X., Hukuda, H., Miyazawa, Y., Yamagata, T., 2003. A Triply Nested Ocean Model for Simulating the Kuroshio - Roles of Horizontal Resolution on JEBAR. Journal of Physical Oceanography 33, 146-169. 
Haynes, R., Barton, E., Pilling, I., 1993. Development, persistence, and variability of upwelling filaments off the Atlantic coast of the Iberian Peninsula. Journal of Geophysical Research 98, 22681-22692.

Hedstrom, K.S., 2009. Technical Manual for a Coupled Sea-Ice/Ocean Circulation Model (Version 3). Technical report. Artic Region Supercomputing Center, University of Alaska Faibanks.

Holland, W.R., 1973. Baroclinic and Topographic Influences on the Transport in the Western Boundary Currents. Geophysical Fluid Dynamics 4, 187-210.

Huthnance, J., 1984. Slope currents and JEBAR. Journal of Physical Oceanography $14,795-810$.

Large, W., Morzel, J., Crawford, G., 1995. Accounting for Surface Wave Distortion of the Marine Wind Profile in Low-Level Ocean Storms Wind Measurements. Journal of Physical Oceanography 25, 2959-2971.

Large, W.G., McWilliams, J.C., Doney, S.C., 1994. Oceanic vertical mixing: A review and a model with a nonlocal boundary layer parameterization. Reviews of Geophysics 32, 363-403. doi:10.1029/94RG01872.

Le Cann, B., Serpette, A., 2009. Intense warm and saline upper ocean inflow in the southern Bay of Biscay in autumn-winter 2006-2007. Continental Shelf Research 29, 1014-1025.

Lee, S., Pelegri, J.L., Kroll, J., 2001. Slope Control in Western Boundary Currents. Journal of Physical Oceanography 31, 3349-3360.

Liu, W.T., Katsaros, K.B., Businger, J.A., 1979. Bulk Parameterization of AirSea Exchanges of Heat and Water Vapor Including the Molecular Constrains at the Interface. Journal of Atmospheric Sciences 36, 1722-1735.

Llope, M., Anadón, R., Viesca, L., Quevedo, M., González-Quirós, R., Stenseth, 965 N., 2006. Hydrography of the southern Bay of Biscay shelf-break region: Inte- 
grating the multiscale physical variability over the period 1993-2003. Journal of Geophysical Research 111, C09021.

Locarnini, R., Mishonov, A., Antonov, J., Boyer, T., Garcia, H., 2006. World Ocean Atlas 2005 Volume 1: Temperature. U.S. Government Printing Office, Washington, D.C.

Marchesiello, P., McWilliams, J.C., Shchepetkin, A., 2001. Open boundary conditions for long-term integration of regional oceanic models. Ocean Modelling $3,1-20$.

Martins, C., Hamann, M., Fiúza, A., 2002. Surface circulation in the Eastern North Atlantic, from drifters and altimetry. Journal of Geophysical Research 107, 3217. Doi:10.1029/2000JC000345.

Mertz, G., Wright, D.G., 1992. Interpretations of the JEBAR term. Journal of Physical Oceanography 22, 301-305.

Neves, F., 2010. Dynamics and hydrology of the Tagus Estuary: results from in situ observations. Ph.D. thesis. Universidade de Lisboa.

Oliveira, P., Peliz, A., Dubert, J., Rosa, T., Santos, A., 2004. Winter geostrophic currents and eddies in the western Iberia coastal transition zone. Deep Sea Research I 51, 367-381.

Otero, P., Ruiz-Villarreal, M., Peliz, A., Cabanas, J., 2010. Climatology and reconstruction of runoff time series in northwest Iberia: influence in the shelf buoyancy budget off Ría de Vigo. Scientia Marina 74, 247-266.

Peliz, A., Boutov, D., Cardoso, R., Delgado, J., Soares, P., 2012. The Gulf of Cadiz-Alboran Sea sub-basin: Model setup, exchange and seasonal variability. Ocean Modelling 61, 49-67. doi:10.1016/j.ocemod.2012.10.007.

Peliz, A., Dubert, J., Haidvogel, D., 2003a. Subinertial response of a density driven eastern boundary poleward current to wind forcing. Journal of Physical Oceanography 33, 1633-1650. 
Peliz, A., Dubert, J., Haidvogel, D., Le Cann, B., 2003b. Generation and unstable evolution of a density-driven eastern poleward current. Journal of

Pingree, R., Le Cann, B., 1990. Structure, strength and seasonality of the slope currents in the Bay of Biscay region. Journal of the Marine Biology Association of U.K. 70, 857-885.

Pingree, R., Le Cann, B., 1992a. Anticyclonic eddy X91 in the southern Bay 1015 Geophysical Research 108, 3268. Doi:10.1029/2002JC001443.

Peliz, A., Dubert, J., Marchesiello, P., Teles-Machado, A., 2007. Surface circulation in the Gulf of Cadiz: Model and mean flow structure. Journal of Geophysical Research (Oceans) 112, C11015. doi:10.1029/2007JC004159.

Peliz, A., Dubert, J., Santos, A., Oliveira, P., Le Cann, B., 2005. Winter upper ocean circulation in the Western Iberian Basin - Fronts, Eddies and Poleward Flows: an overview. Deep Sea Research I 52, 621-646.

Peliz, A., Rosa, T.L., Santos, A.M.P., Pissarra, J.L., 2002. Fronts, jets, and counter flows in the Western Iberian upwelling system. Journal of Marine Systems 35, 61-77.

Penven, P., Debreu, L., Marchesiello, P., McWilliams, J., 2006. Evaluation and application of the ROMS 1-way embedding procedure to the central california upwelling system. Ocean Modelling 12, 157-187.

Penven, P., Marchesiello, P., Debreu, L., Lefevre, J., 2008. Software tools for preand post-processing of oceanic regional simulations. Environmental Modelling \& Software 23, $660-662$.

of Biscay, May 1991 to February 1992. Journal of Geophysical Research 97, $14353-14367$.

Pingree, R., Le Cann, B., 1992b. Three anticyclonic Slope Water Oceanic eDDIES (SWODDIES) in the Southern Bay of Biscay in 1990. Deep-Sea Research I 39, 1147-1175. 
Prieto, E., González-Pola, C., Lavín, A., Sánchez, R., Ruiz-Villarreal, M., 2013.

Seasonality of intermediate waters hydrography west of the Iberian Peninsula from an 8 yr semiannual time series of an oceanographic section. Ocean Science 9, 411-429.

Qu, T., Gao, S., Fukumoru, I., 2011. What governs the North Atlantic salinity maximum in a global GCM? Geophysical Research Letters 38, L07602.

Relvas, P., Barton, E., 2002. Mesoscale patterns in the Cape São Vicente (Iberian Peninsula) upwelling region. Journal of Geophysical Research 107, 3164. Doi:10.1029/2000JC000456.

Sanz, J.L., Acosta, J., Esteras, M., Herranz, P., Palomo, C., Sandoval., N., 1991. Prospección geofísica del Estrecho de Gibraltar (Resultados del programa Hércules 1980-1983). Publicaciones especiales del Instituto Español de Oceanografía. Instituto Español de Oceanografía.

Shchepetkin, A.F., McWilliams, J.C., 2003. A method for computing horizontal pressure-gradient force in an oceanic model with a non-aligned vertical coordinate. Journal of Geophysical Research - Oceans 108, 3090.

Shchepetkin, A.F., McWilliams, J.C., 2005. The regional oceanic modeling system (ROMS): a split-explicit, free-surface, topographyfollowing-coordinate oceanic model. Ocean Modelling 9, 347-404. doi: $10.1016 /$ j.ocemod.2004.08.002

Smith, W., Sandwell, D., 1997. Global sea floor topography from satellite altimetry and ship depth soundings. Science 277, 1956 - 1962. doi $10.1126 /$ science.277.5334.1956

Soares, P., Cardoso, R., Miranda, P., Medeiros, J., Belo-Pereira, M., EspiritoSanto, F., 2012. WRF high resolution dynamical downscaling of ERA-Interim for Portugal. Climate Dynamics 110.

Torres, R., Barton, E., 2006. Onset and development of the Iberian poleward flow along the Galician coast. Continental Shelf Research 26, 1134-1153. 
Wilkin, J.L., 2006. The Summertime Heat Budget and Circulation of Southeast

New England Shelf Waters. Journal of Physical Oceanography 36, 1997-2011. 

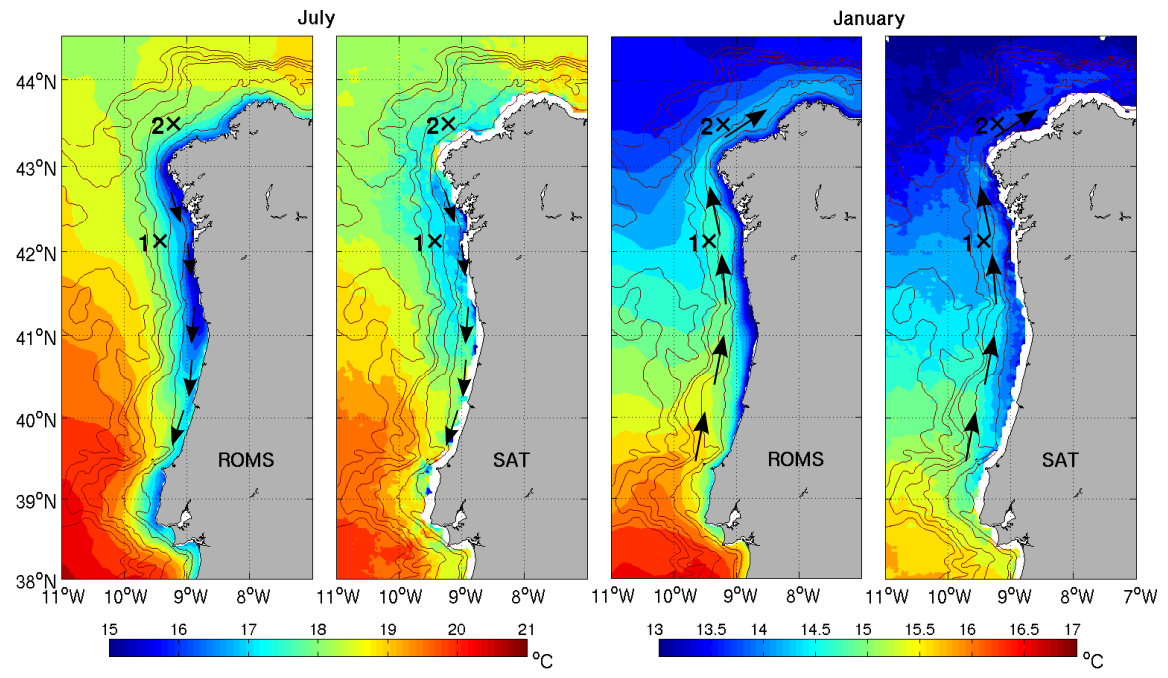

Figure 1: Average SST fields for July (left) and January (right), obtained averaging the 20year model output, and 20-year PATHFINDER satellite data. The arrows are a schematic representation of the average typical currents: southward flowing upwelling jet in July, and northward flowing IPC in January. The crosses 1 and 2 represent the position of 2 moored buoys. 


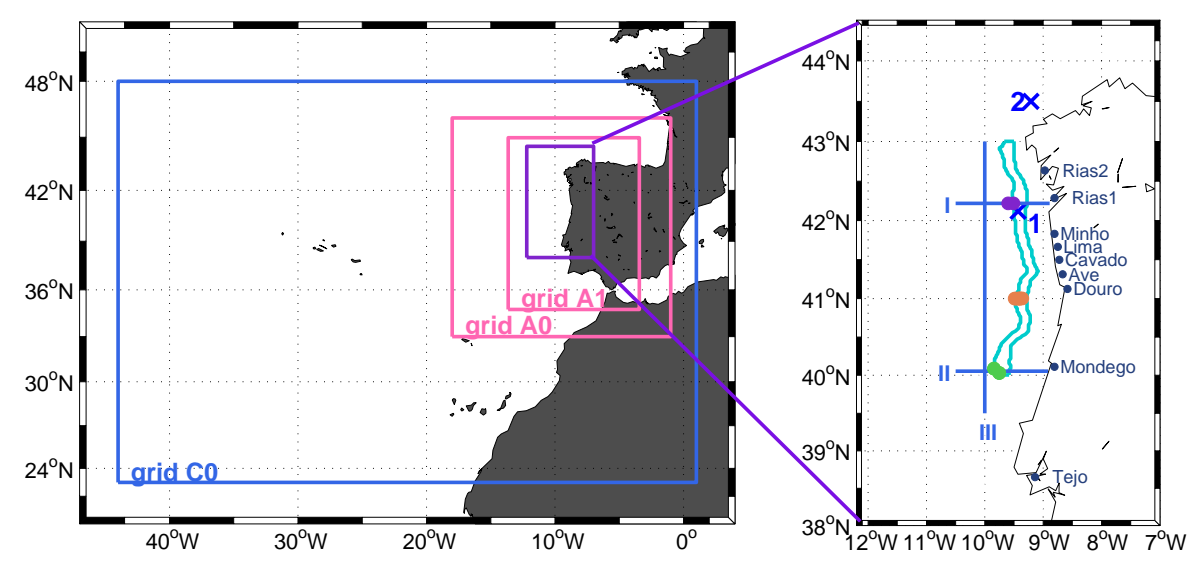

Figure 2: On the left: Map showing the 3 spatial domains used in the model configuration (Grids $\mathrm{C} 0$, A0 and A1). On the right: a zoom on the coastal margin we are focusing on. The name of the rivers considered in the simulation are indicated. Two sections (I and II, respectively at $42.2^{\circ} \mathrm{N}$ and $40.1^{\circ} \mathrm{N}$ ) will be referred in the text to show the velocity structure, the purple, orange and green dots represent the current meter observations. The crosses 1 and 2 represent the position of 2 moored buoys. The cyan zone over the slope will be used to compute area integrated vorticity budgets.

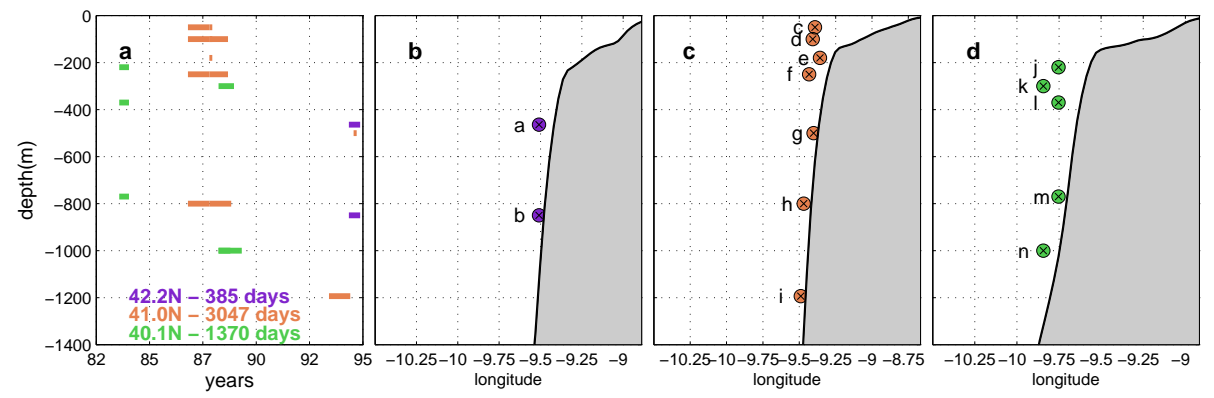

Figure 3: (a) Time-depth distribution of all the current meter data available. Data from three different latitudes (42.2, 41.0, 40.1 - positions in Fig. 2) is plotted with different colors. The inset shows the total number of days of data available for each latitude (sum of the various depths).(b-d) position of the currentmeters for each latitude. 


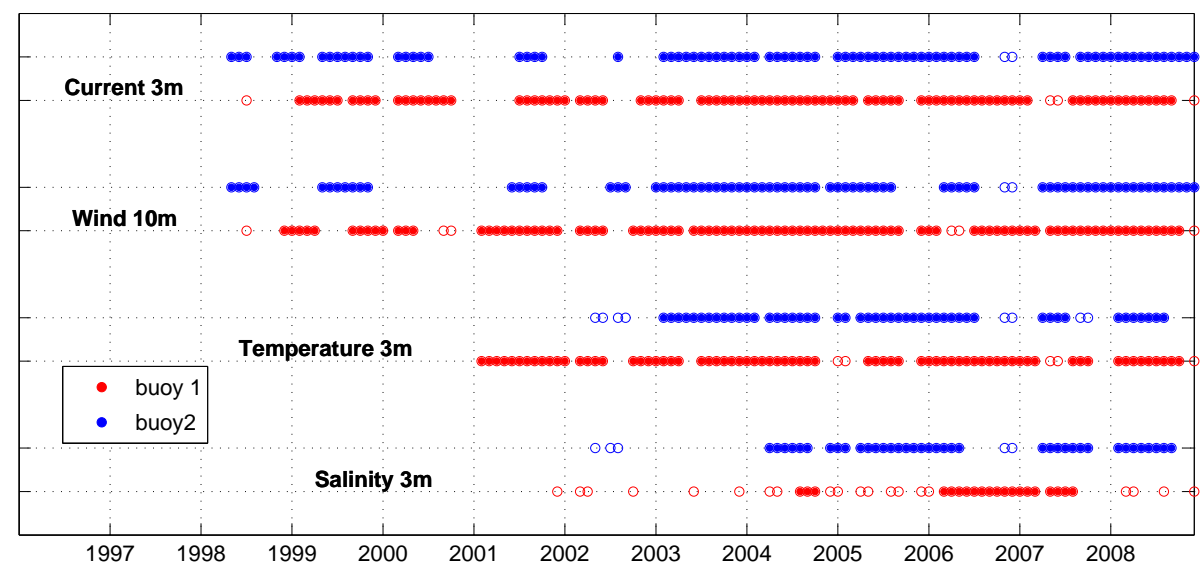

Figure 4: Time distribution of months with data available at the buoys, of wind at $10 \mathrm{~m}$ height, and currents, temperature and salinity at $3 \mathrm{~m}$ depth. Buoy 1 in blue and Buoy 2 in red (see location on Fig. 2). The months used to compute the seasonal cycles displayed in Fig. 6 are represented with filled circles. Periods with less than 3 consecutive months of available data (open circles) were not considered for the computation of the seasonal cycle. 


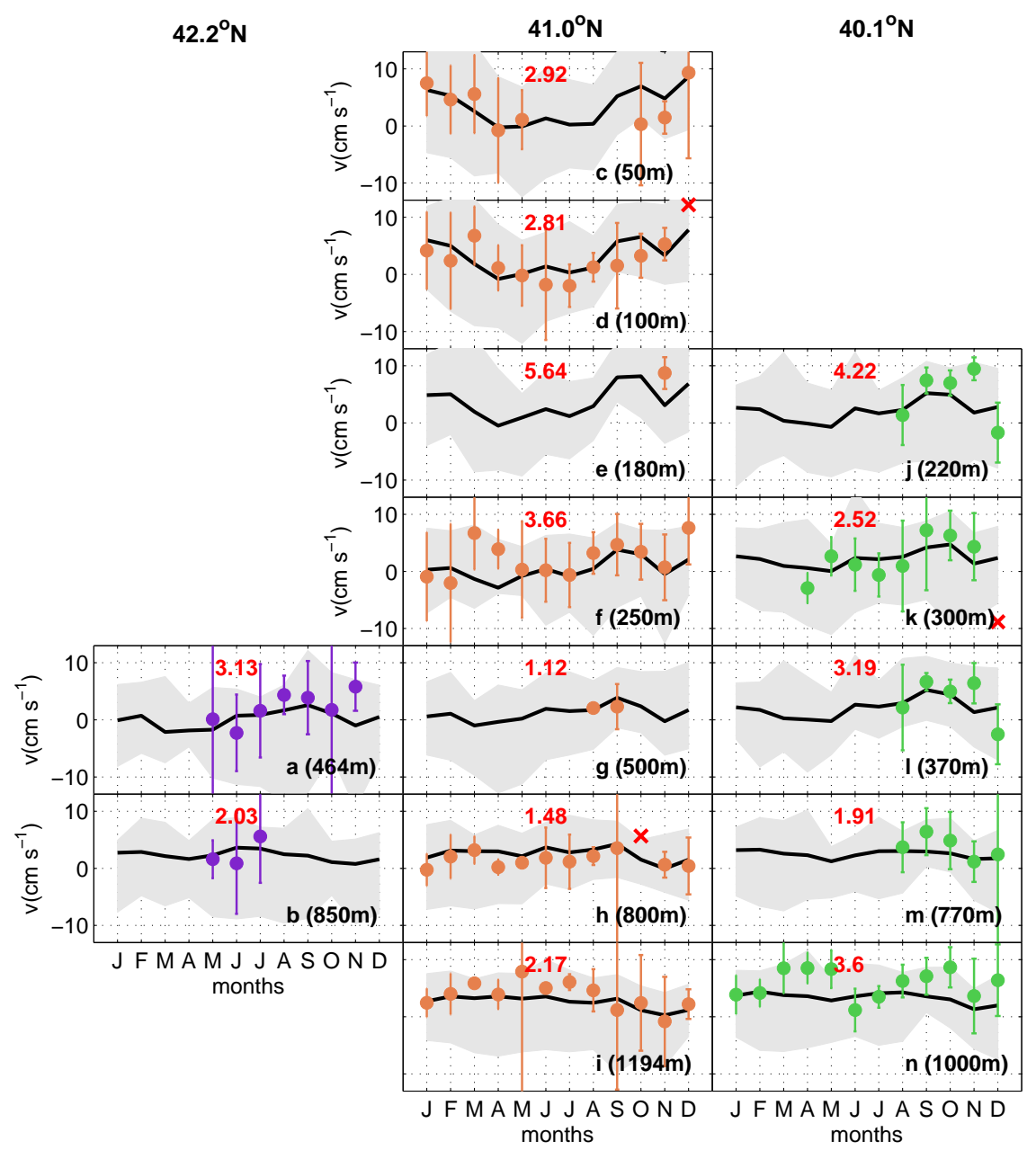

Figure 5: Comparison of meridional currents $\left(\mathrm{cm} \mathrm{s}^{-1}\right)$ from current meter monthly averages and model results. Each subplot corresponds to a current meter location. The left column shows current meters at $42.2^{\circ} \mathrm{N}$ (purple), the middle at $41.0^{\circ} \mathrm{N}$ (orange), and the right at $40.1^{\circ} \mathrm{N}$ (green). Lowercase letters in the subplots correspond to the currentmeters letters in Fig. 3 (b-d)). Black line - monthly averages of the model. Grey shading - maximum and minimum monthly averages from the entire 20-year model run. Dots - monthly averages obtained from the current meters. Bars - uncertainty in the estimation of current meter mean, following a t-student distribution. The number in red represents the root mean square error as a measure of the difference between observations and model (the red crosses were not considered to compute the RMSe because their values were more than 2 standard deviations away from the current meter mean for each plot) 

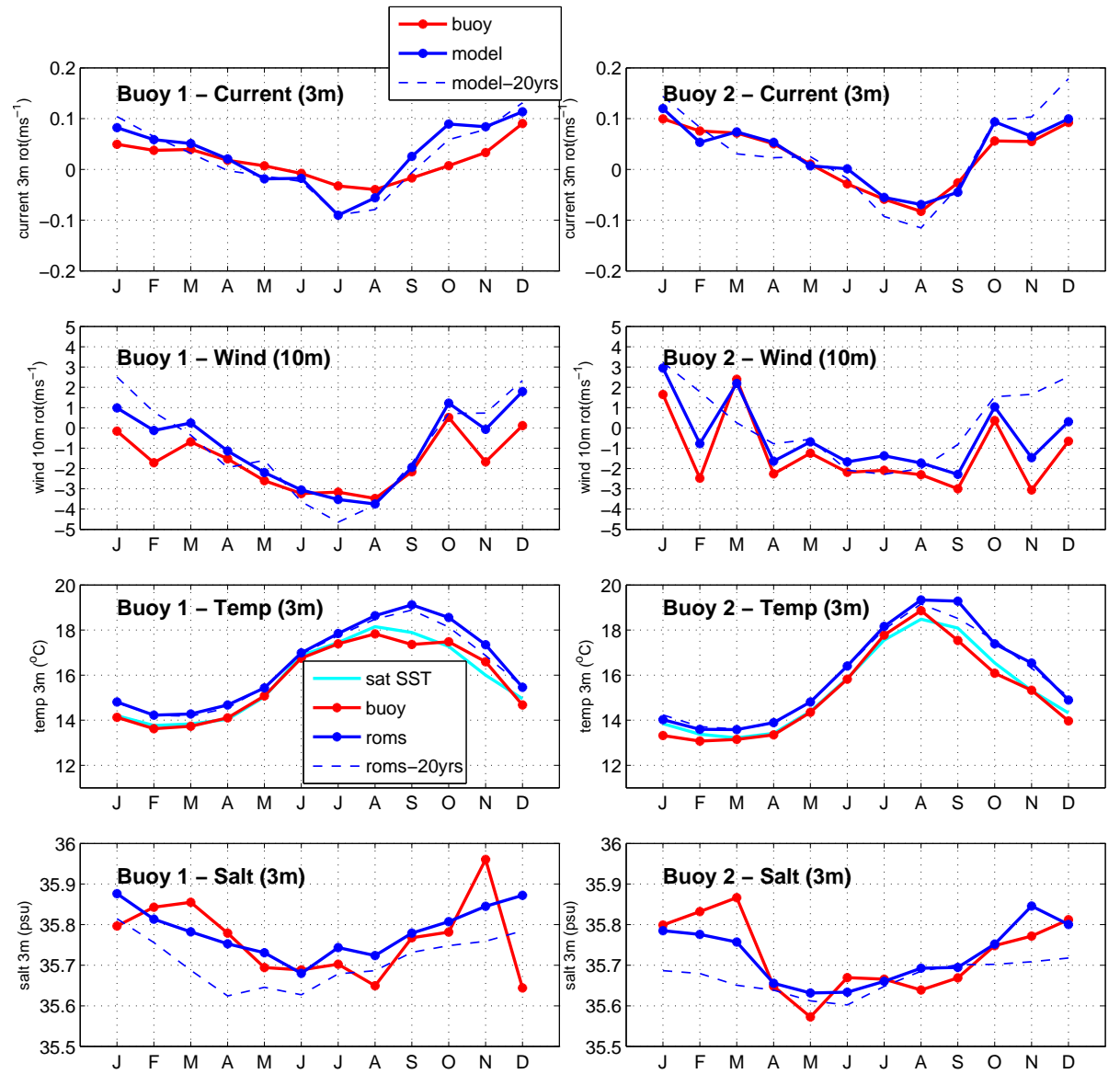

Figure 6: Comparison of alongshore currents, winds, temperature and salinity, between model and observations, in buoys 1 and 2 (see location on Fig. 2). 1st row: comparison of $3 \mathrm{~m}$ depth currents. 2nd row: comparison of $10 \mathrm{~m}$ height winds. 3rd row: comparison of $3 \mathrm{~m}$ depth temperature and also satellite SST in the same locations. 4th row: comparison of $3 \mathrm{~m}$ depth salinity. The red line represents the monthly averages of the observations. The blue continuous line represents the monthly averages of the model considering only the years and months when there were observations available. The blue dashed line represents the monthly averages of the model considering the entire period of the simulation. 

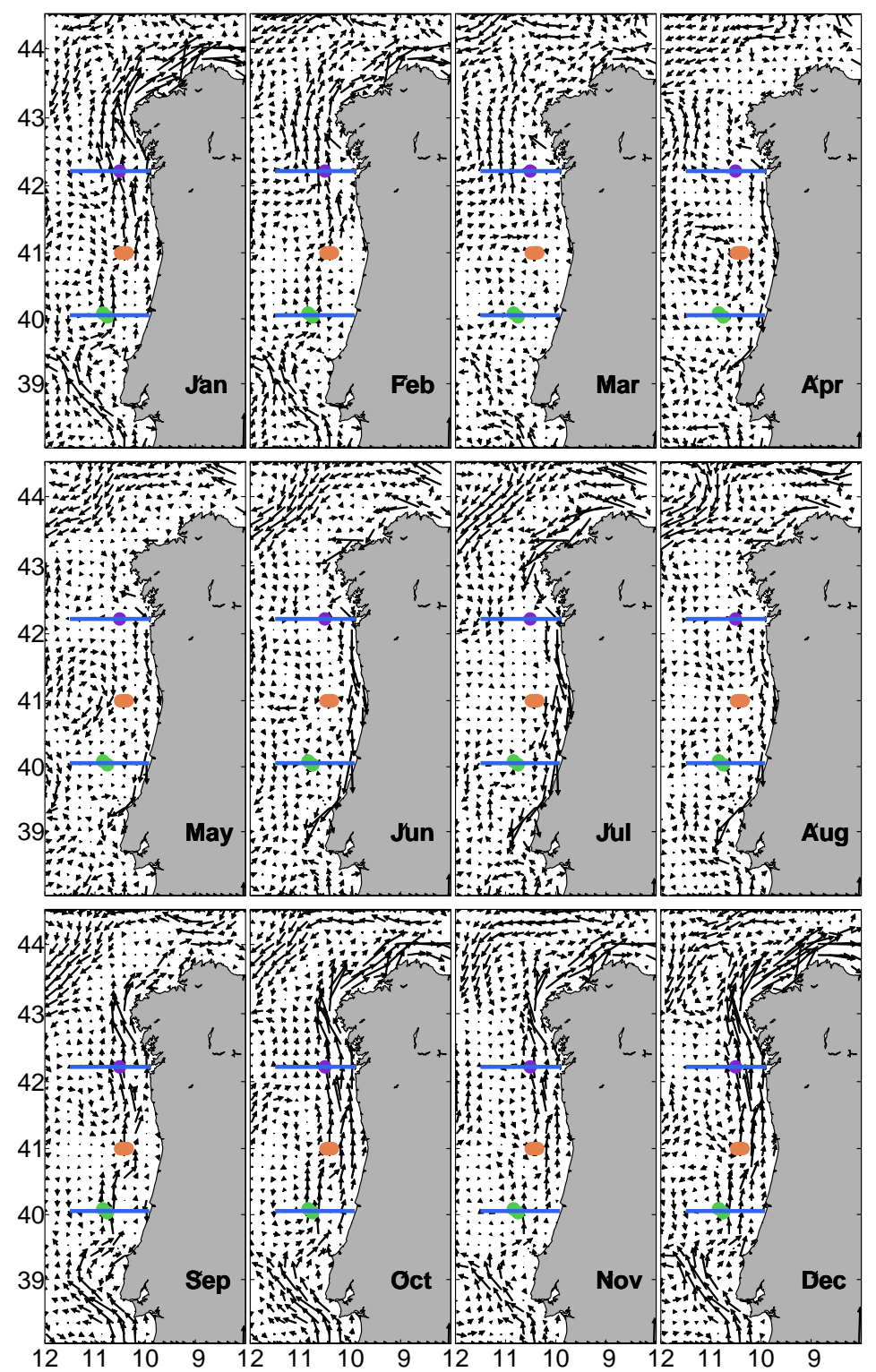

Figure 7: Monthly mean fields of the depth-averaged velocity for the top $350 \mathrm{~m}$ (or from the surface down to the bottom in sites shallower than $350 \mathrm{~m}$ ). The blue lines and purple, orange and green points correspond to the sections and current meters positions shown in Fig. 2 


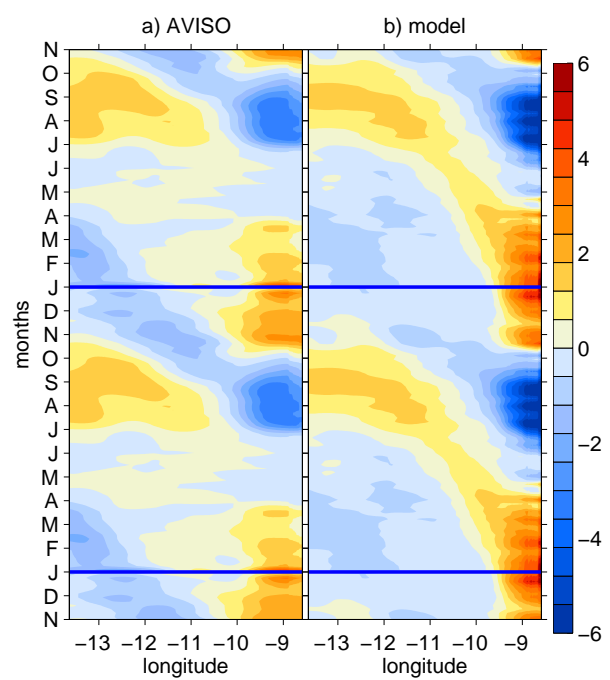

Figure 8: Hovmoller diagrams of SSHa $(\mathrm{cm})$, as a function of longitude and months of the year. SSHa was meridionally averaged from $40^{\circ}$ to $43^{\circ} \mathrm{N}$. a) SSHa from altimetry (AVISO). b) SSHa from model. Note that the parts above and below the blue lines replicate the monthly averages to facilitate the perception of the seasonal cycle. 


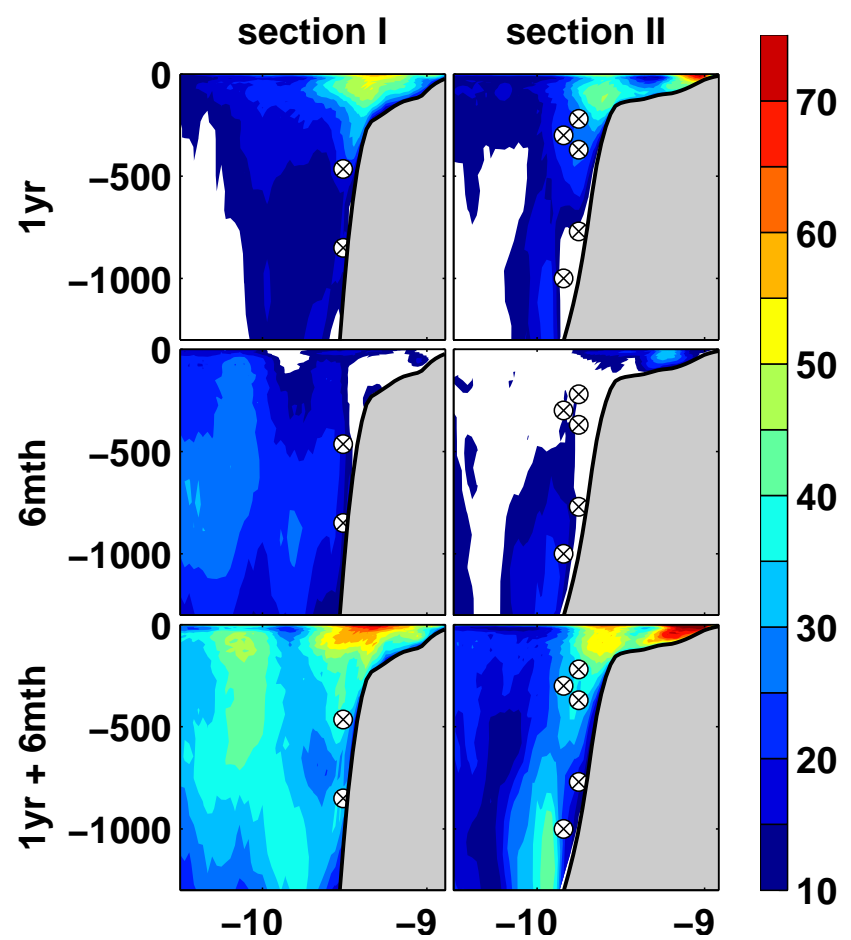

Figure 9: Percentage (\%) of standard deviation relative to seasonal and 6-month variability of model alongshore currents. Sections I and II (Fig. 2) are represented in the two columns. First row - percentage of variability of the 1-year period adjusted sinusoid. Second row percentage of variability of the half-year period adjusted sinusoid. Third row - sum of both, total variability explained by the seasonal frequency and its first harmonic. Areas in white variability explained by that component is $<10 \%$. The circles with a cross show the positions of the current meters (same as Fig. 3). 


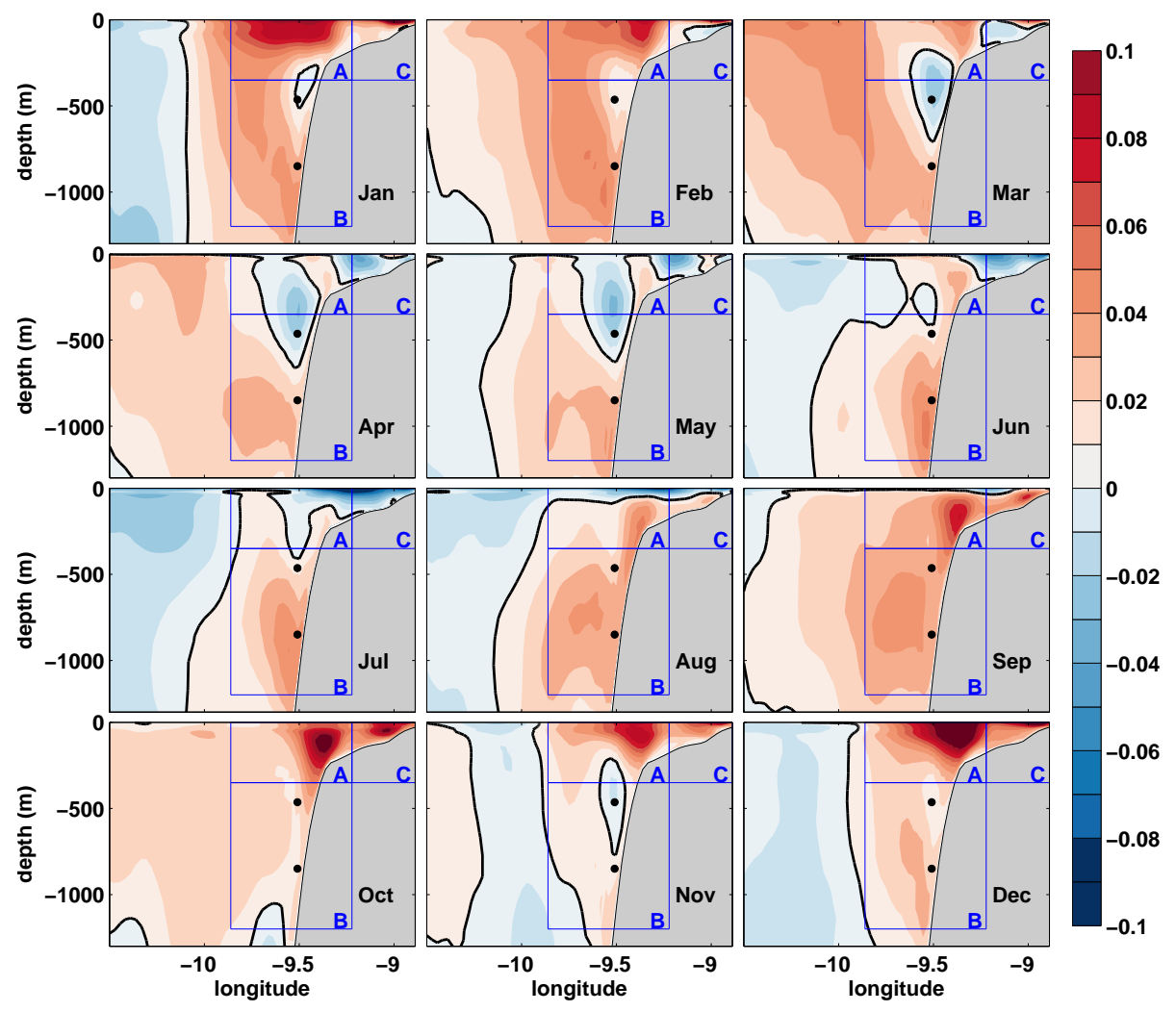

Figure 10: Section I (see Fig. 2) - Vertical sections of the monthly averages of 20-years simulation of alongshore velocities $\left(\mathrm{m} \mathrm{s}^{-1}\right)$ - positive values correspond to northward flow. The black dots represent the position of the current meters available for the section. The 3 areas delimited with blue boxes $(\mathrm{A}, \mathrm{B}, \mathrm{C})$ are used to compute integrated transport in section 3.2 .3 


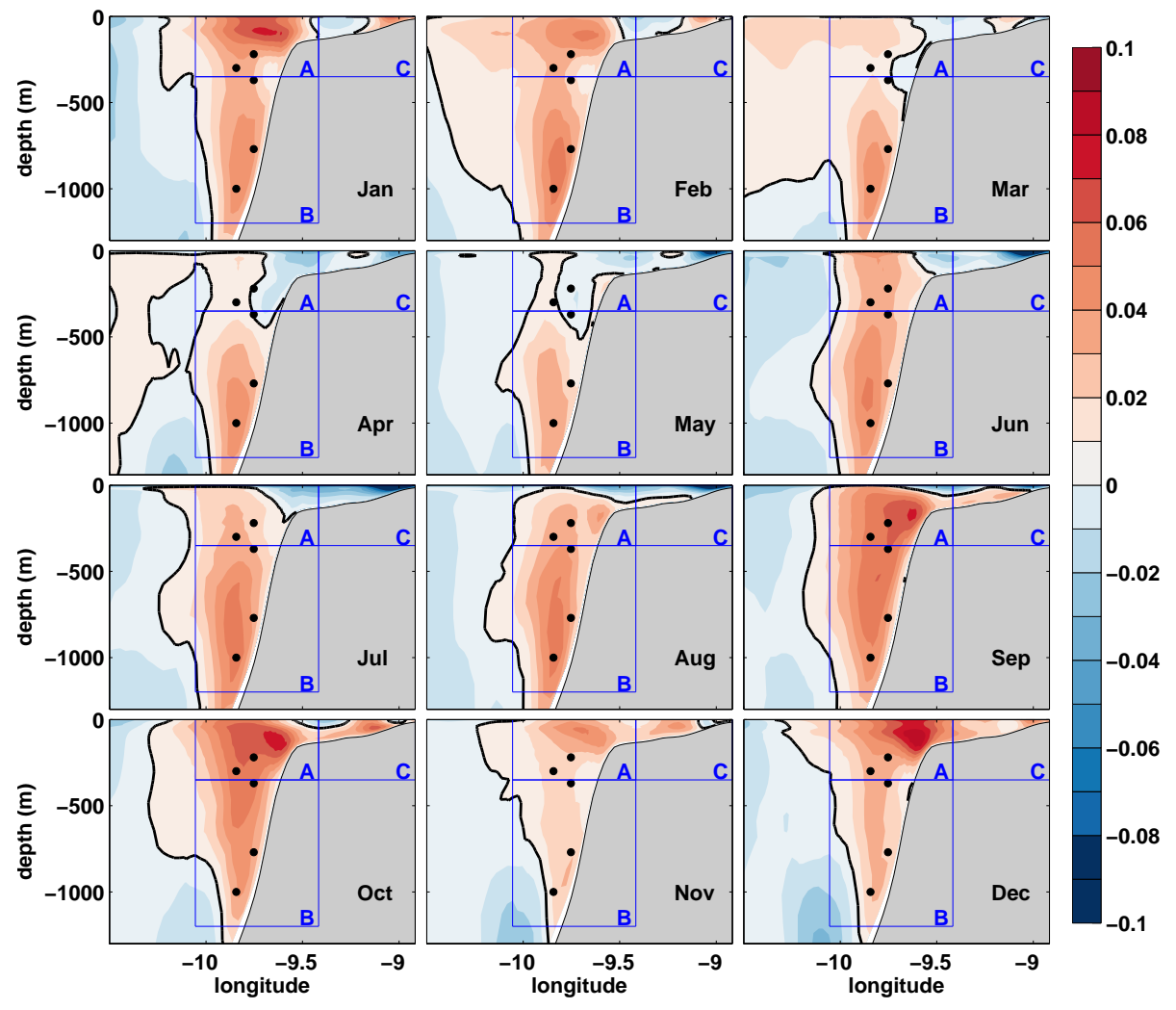

Figure 11: The same as Fig. 10 for section II (see location on Fig. 22). 


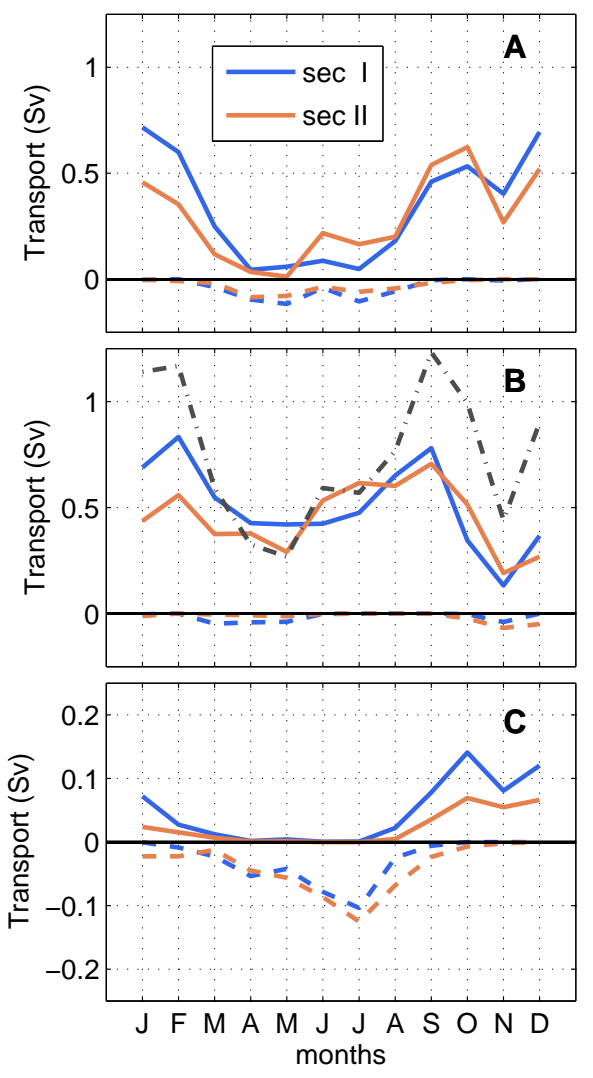

Figure 12: Seasonal cycle of the meridional transport $\left(\mathrm{Sv}=10^{6} \mathrm{~m}^{3} \mathrm{~s}^{-1}\right)$ across different areas and for sections I and II (Fig. 2). The areas A(upper slope), B(deep slope) and C(shelf) are shown in figures 10 and 11 for section I and II, respectively. Colors correspond to the different sections. Continuous lines represent northward transport (obtained considering only positive velocities) and dashed lines represent southward transport (obtained considering only negative velocities). The dashed-dotted gray line in the middle subplot represents the total net transport (north+south) of the slope area $(\mathrm{A}+\mathrm{B})$ averaged between the 2 sections. 

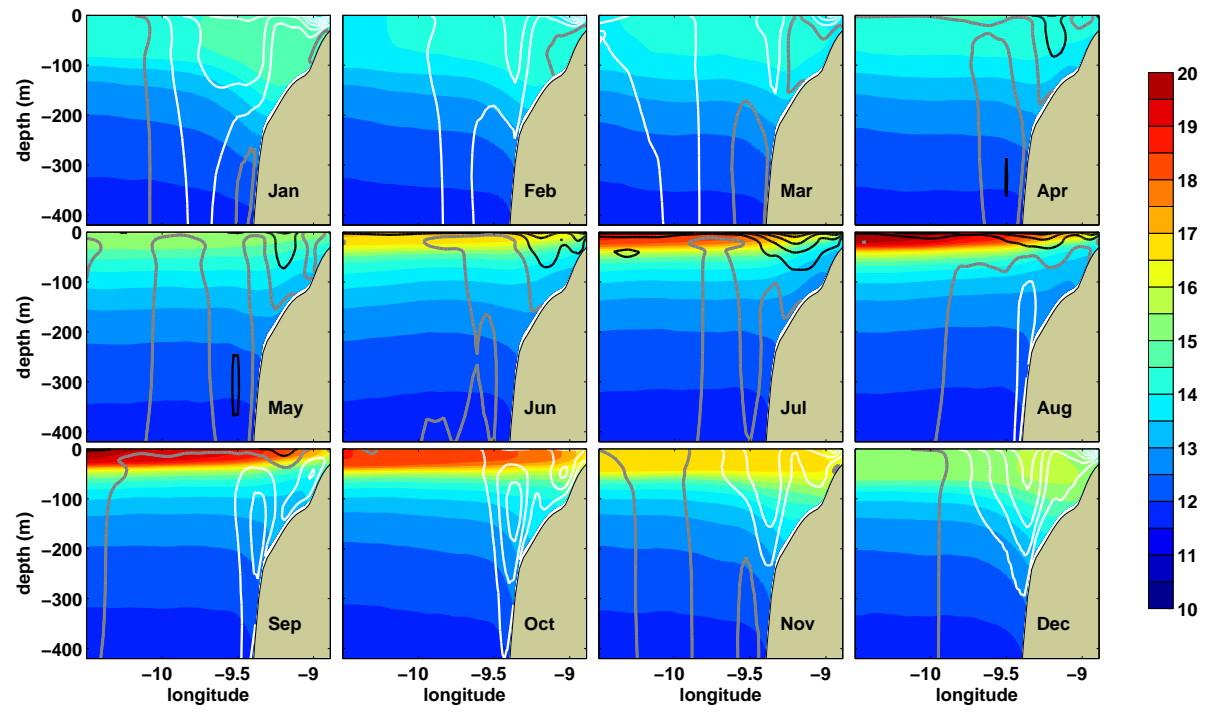

Figure 13: Section I (see Fig. 2) - Vertical sections of the monthly averages of 20-years simulation of temperature $\left({ }^{\circ} \mathrm{C}\right)$ in colors and meridional velocities (contours). The velocity contours have an interval of $0.03 \mathrm{~ms}^{-1}$; positive values are displayed on a white line, negative on a black line, and zero is in gray. 

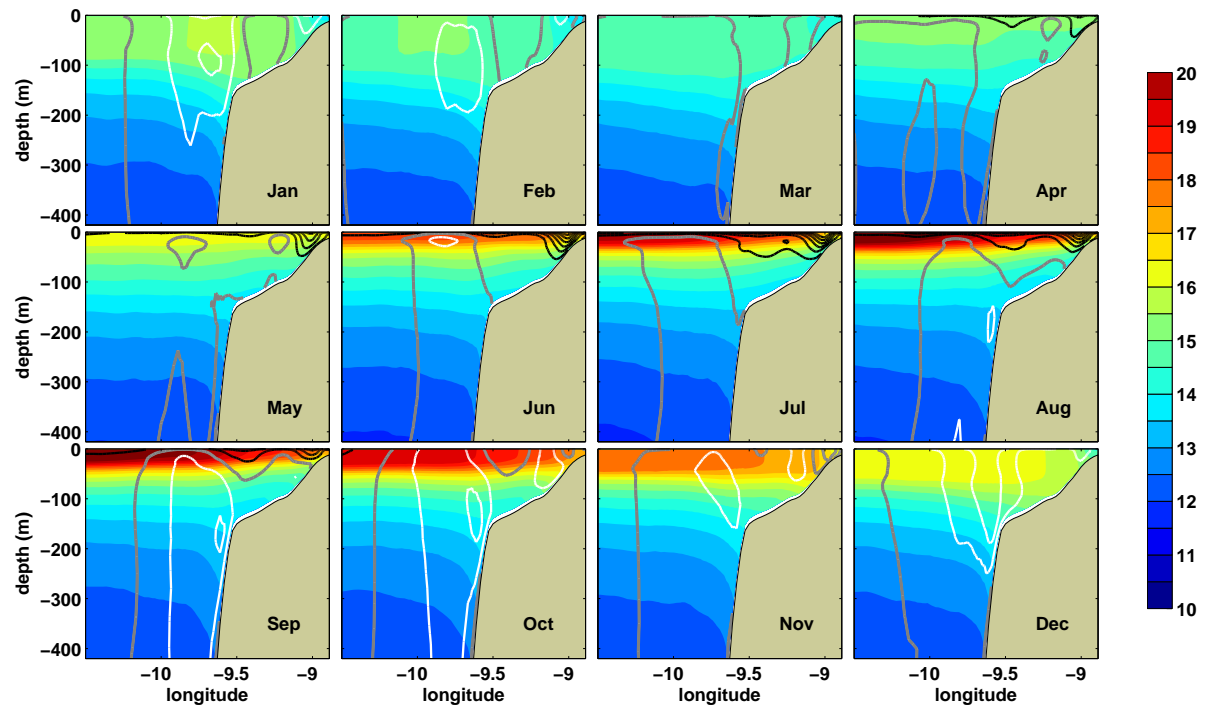

Figure 14: Section II (see Fig. 2) - Vertical sections of the monthly averages of 20-years simulation of temperature $\left({ }^{\circ} \mathrm{C}\right)$ in colors and meridional velocities (contours). The velocity contours have an interval of $0.03 \mathrm{~ms}^{-1}$; positive values are displayed on a white line, negative on a black line, and zero is in gray. 

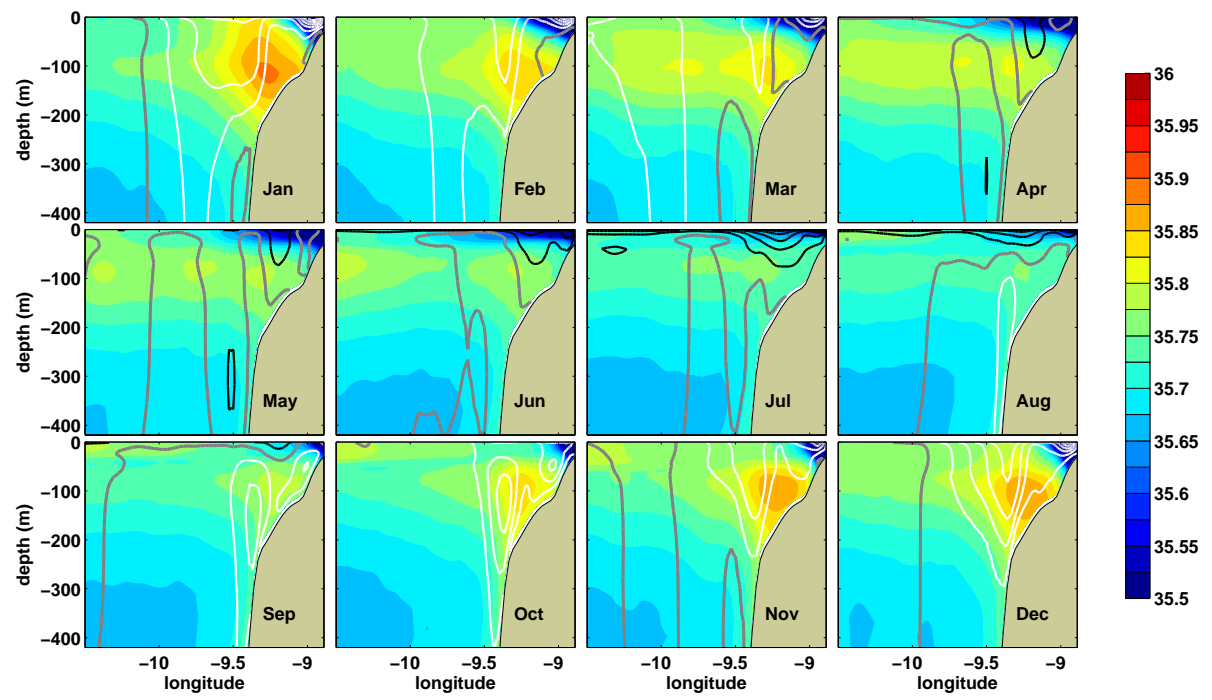

Figure 15: Section I (see Fig. 2) - Vertical sections of the monthly averages of 20-years simulation of salinity (PSS) in colors and meridional velocities (contours). The velocity contours have an interval of $0.03 \mathrm{~ms}^{-1}$; positive values are displayed on a white line, negative on a black line, and zero is in gray. 

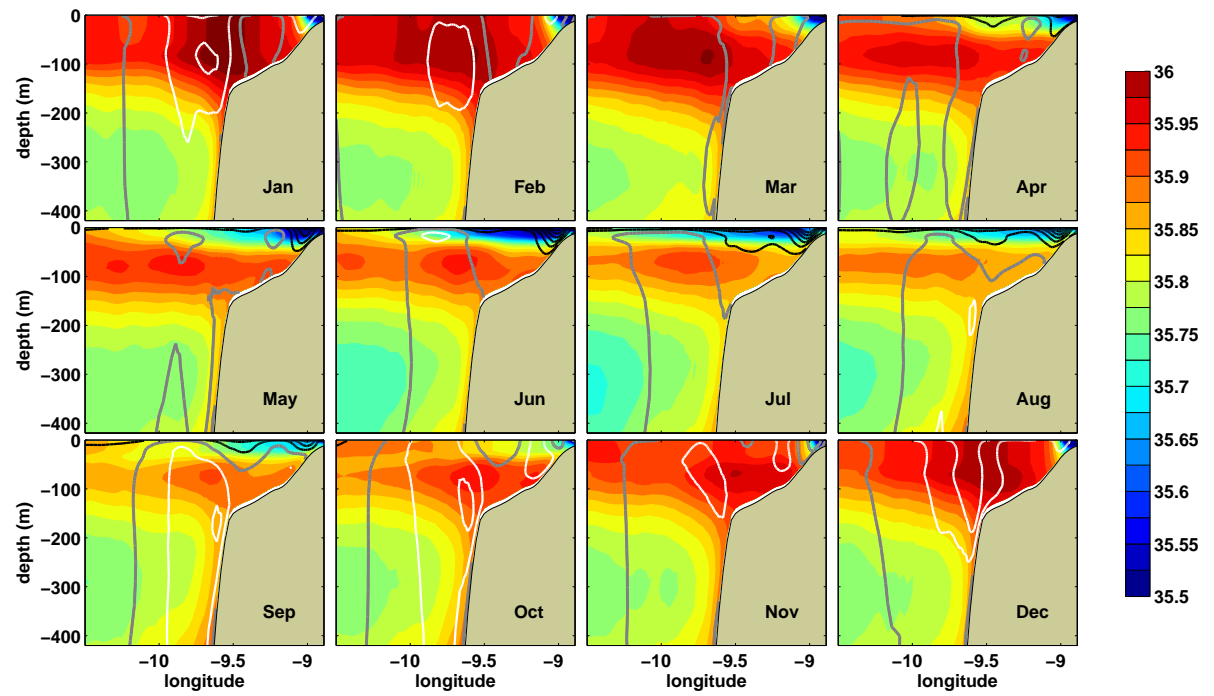

Figure 16: Section II (see Fig. 21) - Vertical sections of the monthly averages of 20-years simulation of salinity (PSS) in colors and meridional velocities (contours). The velocity contours have an interval of $0.03 \mathrm{~ms}^{-1}$; positive values are displayed on a white line, negative on a black line, and zero is in gray. 


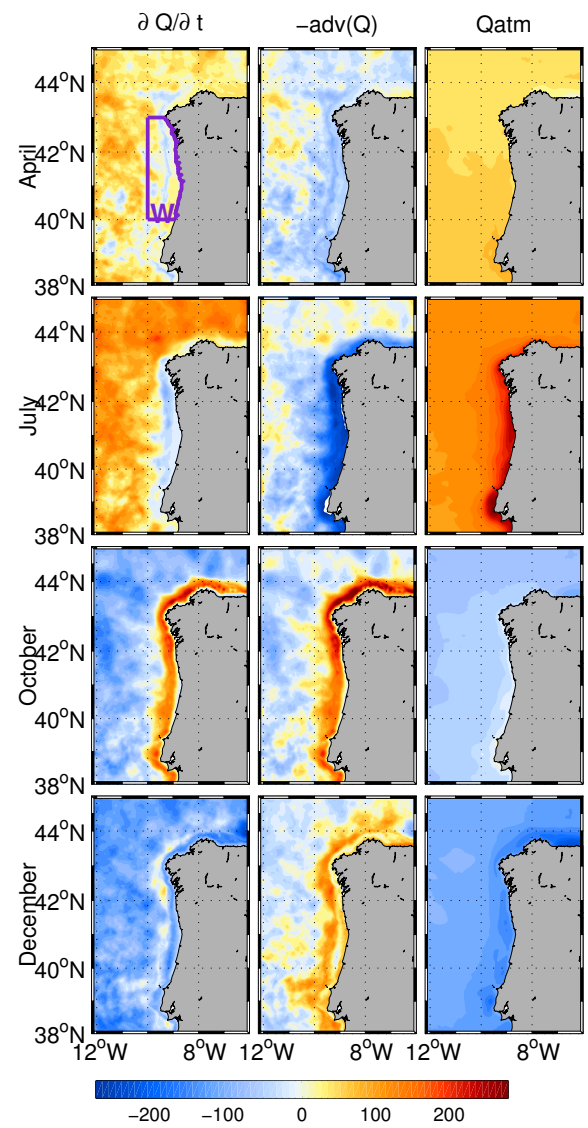

a)

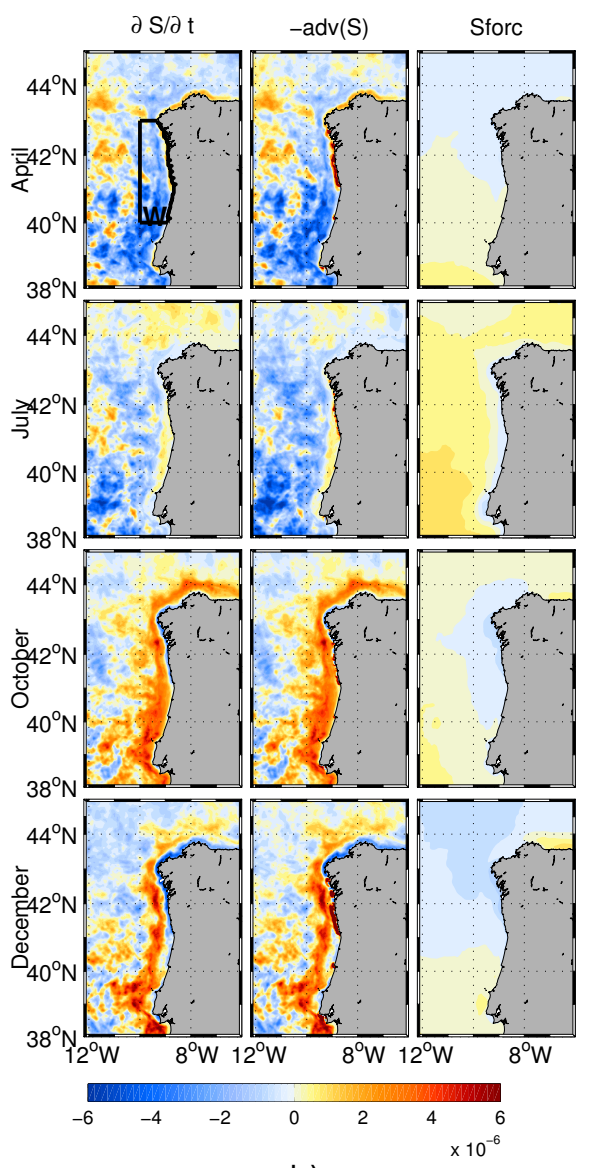

b)

Figure 17: a) global averaged heat fluxes $\left(W^{-2}\right)$ on the top $200 \mathrm{~m}$ of the water column for April, July, October and December. The columns represent average time rate, advection and atmospheric forcing. b) the same, for salt fluxes $\left(P S S m s^{-1}\right)$. The box $\mathrm{W}$ marks the area used to compute the area averaged budgets. 

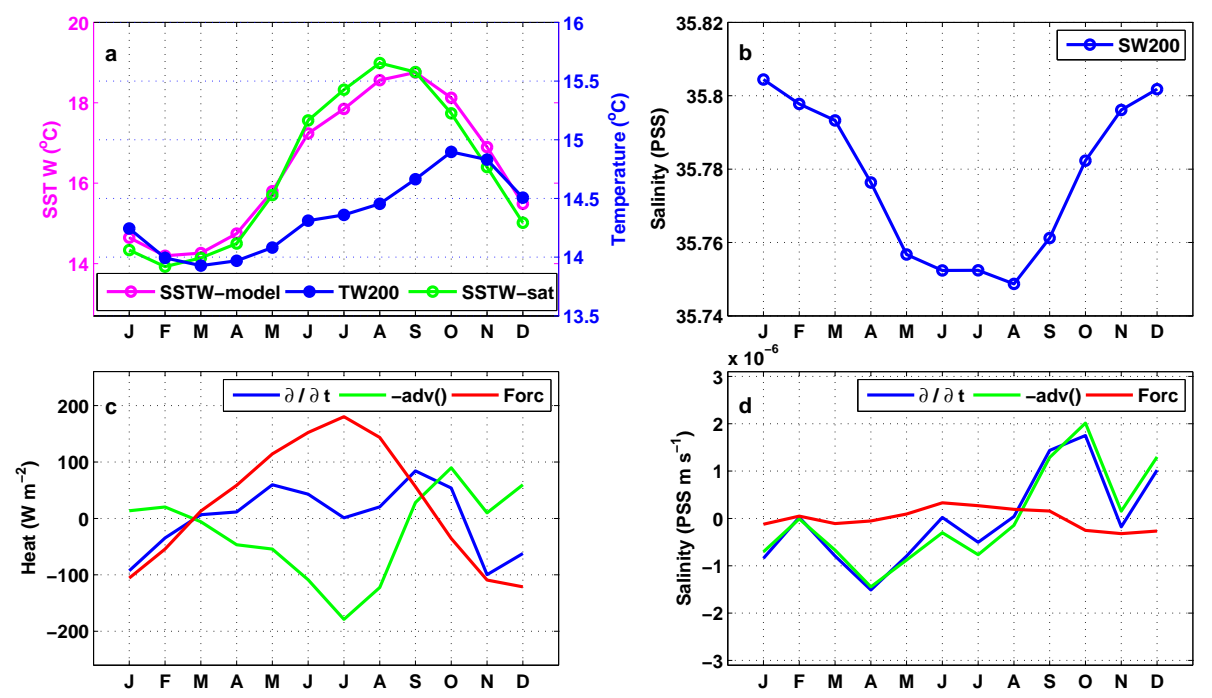

Figure 18: Average seasonal cycle of: (a) volume averaged temperature in the upper $200 \mathrm{~m}$ (model) and SST (model and satellite); (b) volume averaged salinity (top $200 \mathrm{~m}$ ); (c) volume averaged (top $200 \mathrm{~m}$ ) heat budget equation terms; (d) volume averaged salinity budget equation terms. In both (c) and (d) are represented the time rate, the advection and the atmospheric forcing. All quantities are averaged in the domain W (see Fig. 17). 


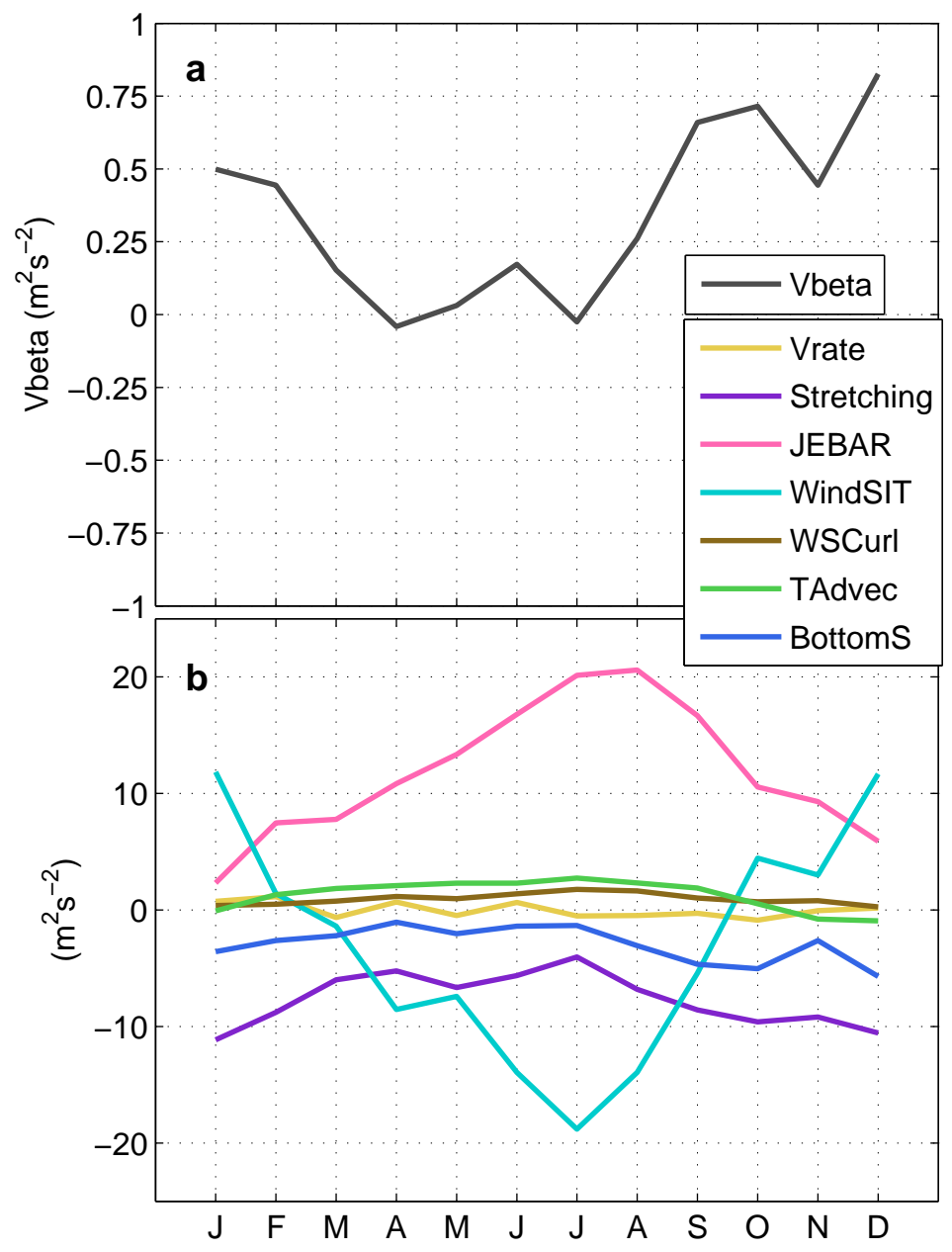

Figure 19: Seasonal cycle of area-integrated values of all terms in Equation $5\left(m^{2} s^{-2}\right)$ monthly averages (terms are multiplied by $10^{12}$ ). The area of integration is shown in Fig. 2 by the cyan line in the zoom plot. (a) Vbeta; (b) terms from the right side of the vorticity equation - Vrate, Stretching, JEBAR, WindSIT, WSCurl, TAdvec and BottomS. Note that the scales of the vertical axes in (a) and (b) are different. 

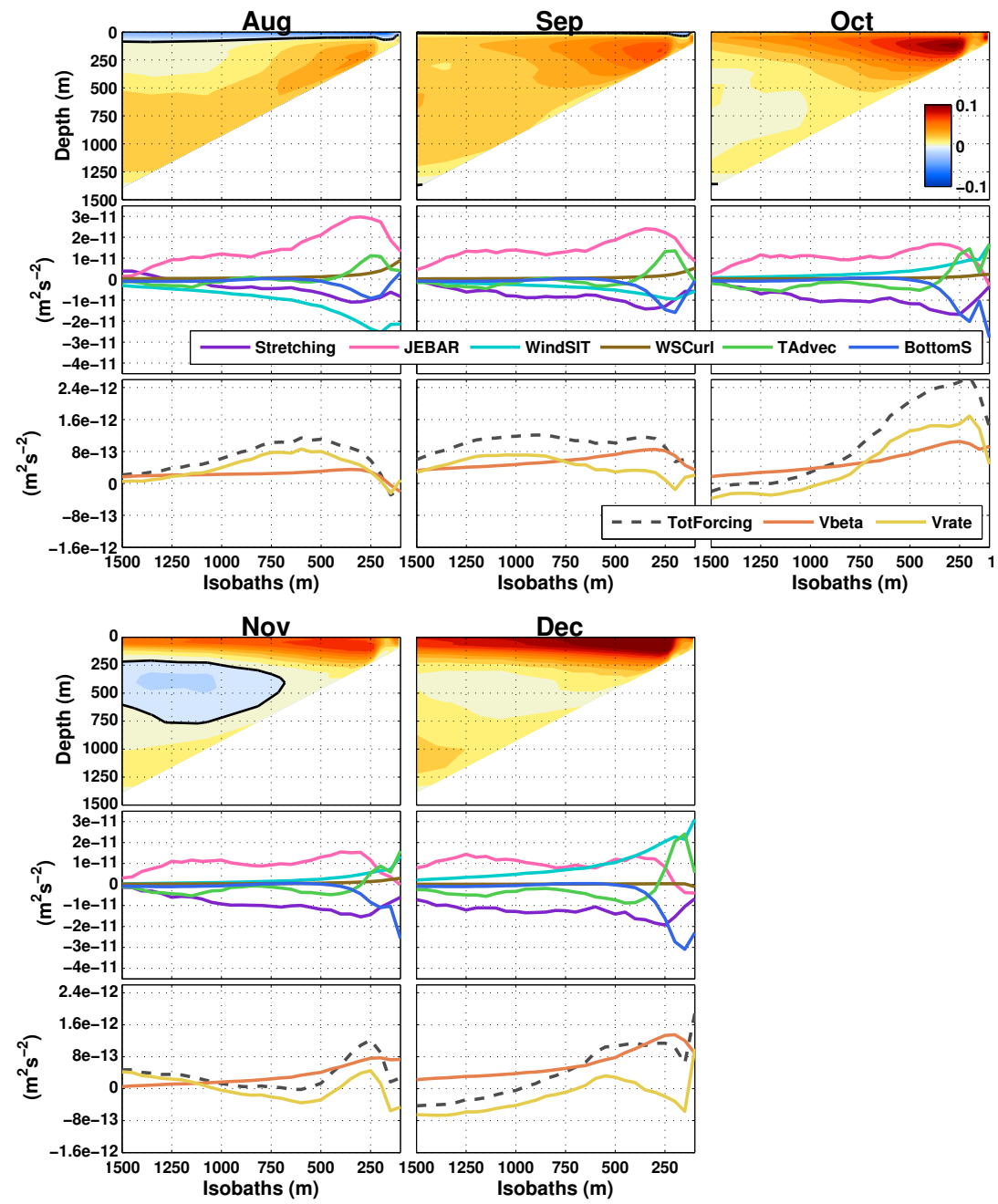

Figure 20: August to December cross-shore structure monthly means. First row: alongshore velocities $\left(\mathrm{m} \mathrm{s}^{-1}\right)$ at $42.2^{\circ} \mathrm{N}$ (same as Fig. 10 but in function of depth). Second row: alongisobath average ( 40 to $43^{\circ} \mathrm{N}$ ) of Stretching, JEBAR, WindSIT, WSCurl, TAdvec and BottomS. Third row: along isobaths average of Vbeta, Vrate and the total forcing (sum of all terms from the second row). 

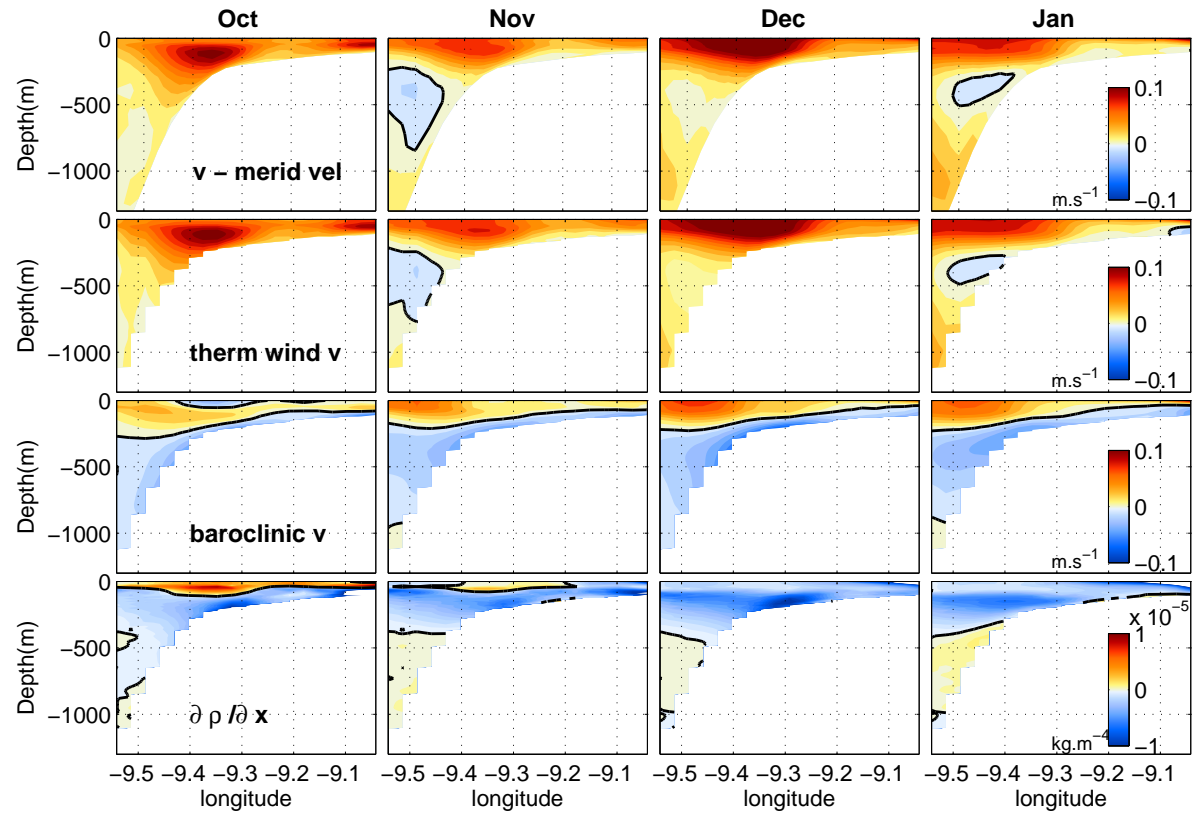

Figure 21: October to January monthly means vertical sections at $42.2^{\circ} \mathrm{N}$ (latitude of section I on Fig. 2). First row: meridional velocity (monthly averages of 20-year simulation; same as Fig. 10 but zoomed only in the slope). Second row: meridional velocity obtained by the thermal wind equation (density field), integrated from the surface and with the surface velocity obtained from the sea surface height gradient. Third row: baroclinic meridional velocity structure (the vertical average was removed at each point from the fields in the second row). Fourth row: zonal density gradient $\partial \rho / \partial x$ (negative values mean $\rho$ decreases to the coast). 


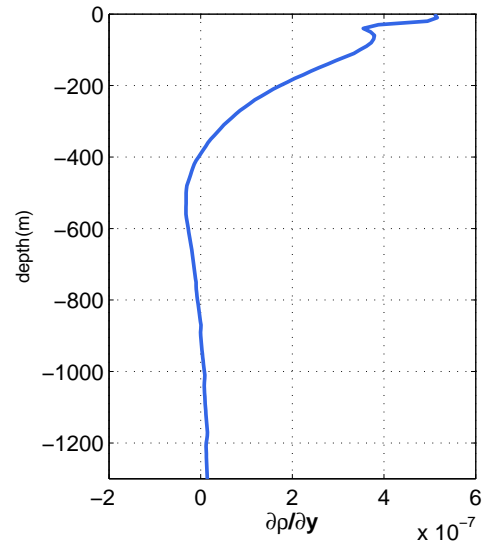

Figure 22: Mean meridional density gradient $\left(\mathrm{kg} \mathrm{m}^{-4}\right)$ obtained in section III (see location in Fig. 2)

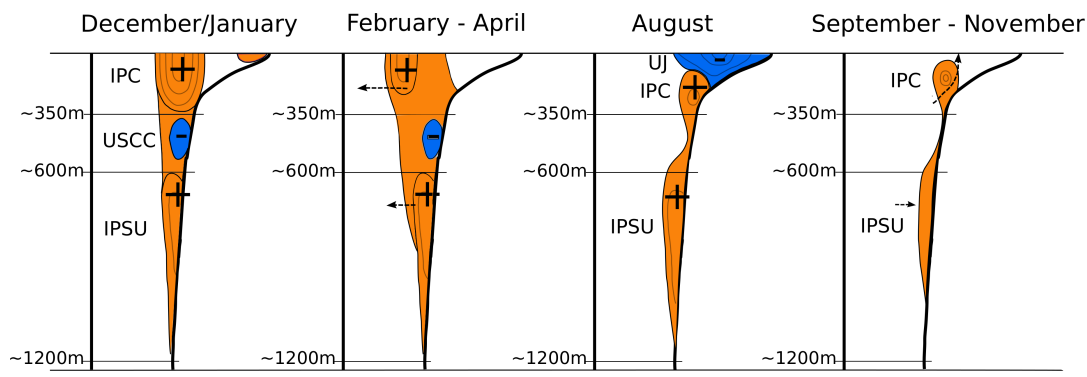

Figure 23: Schematic representation of the seasonal cycle of the alongshore currents. Positive values (orange) correspond to northward flow, negative values (blue) to southward flow. IPC, is Iberian Poleward Current; USCC, is Upper Slope Countercurrent; IPSU, is Iberian Poleward Slope Undercurrent; UJ, is Upwelling Jet. 